WIDER Working Paper 2020/92

\title{
A medium-sized, open-economy, fiscal DSGE model of South Africa
}

Johannes Hermanus Kemp* and Hylton Hollander*

July 2020 
Abstract: Much of the research on fiscal multipliers has used reduced form modelling approaches. While these models have been extended to include richer controls and identification approaches, it remains unclear whether shocks identified capture the true structural shocks. An alternative way to identify these shocks is through dynamic stochastic general equilibrium models. This paper estimates an open-economy dynamic stochastic general equilibrium model for South Africa, but with a more detailed fiscal block, to measure the impact of fiscal policy shocks on macroeconomic outcomes. Simulations indicate that government spending and investment multipliers are generally positive, albeit smaller than 1 . Second, it is found that taxes are highly distortionary, with large negative multipliers for private consumption and investment. In contrast, the impact of tax shocks on output is ambiguous. Finally, simulations suggest that government consumption spending and labour and consumption taxes are the most effective instruments for stabilizing debt after a fiscal shock.

Key words: dynamic stochastic general equilibrium model, fiscal policy, fiscal multiplier, Bayesian inference

JEL classification: C32, E32, E62, H62, H63

Acknowledgements: This paper represents an edited version of a chapter contained in an original $\mathrm{PhD}$ dissertation, entitled Essays on fiscal policy in South Africa, completed at the University of Stellenbosch. Original copyright belongs to the University of Stellenbosch.

*Stellenbosch University, Stellenbosch, South Africa; corresponding author: johannes.kemp@gmail.com

This study has been prepared within the UNU-WIDER project Southern Africa-Towards Inclusive Economic Development (SA-TIED)

Copyright (C) UNU-WIDER 2020

Information and requests: publications@wider.unu.edu

ISSN 1798-7237 ISBN 978-92-9256-849-8

https://doi.org/10.35188/UNU-WIDER/2020/849-8

Typescript prepared by Gary Smith.

The United Nations University World Institute for Development Economics Research provides economic analysis and policy advice with the aim of promoting sustainable and equitable development. The Institute began operations in 1985 in Helsinki, Finland, as the first research and training centre of the United Nations University. Today it is a unique blend of think tank, research institute, and UN agency_providing a range of services from policy advice to governments as well as freely available original research.

The Institute is funded through income from an endowment fund with additional contributions to its work programme from Finland, Sweden, and the United Kingdom as well as earmarked contributions for specific projects from a variety of donors.

Katajanokanlaituri 6 B, 00160 Helsinki, Finland

The views expressed in this paper are those of the author(s), and do not necessarily reflect the views of the Institute or the United Nations University, nor the programme/project donors. 
Much of the research on fiscal multipliers has used reduced form modelling approaches. While these models have been extended to include richer controls and innovative identification approaches in an effort to refine the analysis, a question that often arises is whether shocks identified in these reduced form models, more often than not with minimal theoretical restrictions, capture the true structural shocks.

An alternative, more theoretical, way to identify shocks to government spending and taxes is through estimated dynamic stochastic general equilibrium (DSGE) models. Given their theoretical consistency and inherently forward-looking nature, DSGE models present a useful tool for policy analysis, and fiscal policy analysis in particular. The rational expectations paradigm embedded in the DSGE framework imply that agents' beliefs about which fiscal instruments are used to finance public debt play a crucial role in the determination of the equilibrium as well as the dynamic response of endogenous variables, including output.

In light of these considerations, an open-economy DSGE model in the New Keynesian tradition, but with a more detailed fiscal block, as in Coenen et al. (2013), is estimated in an attempt to improve our understanding of the size (and direction) of the impact of fiscal policy shocks on macroeconomic outcomes in the South African context. Apart from the now standard set of nominal rigidities, the model contains several features that make it suitable for fiscal policy analysis, namely non-Ricardian (or ruleof-thumb) consumers, utility-enhancing government spending, and distortionary taxes.

Policy simulations based on the estimated model indicate that government spending and investment multipliers are generally positive, albeit smaller than 1 . Second, it is found that taxes are highly distortionary, with large negative multipliers for private consumption and investment. In contrast, the impact of tax shocks on output is ambiguous and depends on assumptions regarding the functional form of the different fiscal rules. Finally, an investigation into debt dynamics suggests that government consumption spending and, to a lesser extent, labour and consumption taxes are the most effective instruments for stabilizing debt after a fiscal shock.

The rest of the paper proceeds as follows: Section 2 provides a brief overview of the literature, while Section 3 provides details on the DSGE model. Section 4 provides details on the estimation procedure as well as estimation results. Section 5 presents various simulation results, including fiscal multiplier analysis, and Section 6 concludes with some final thoughts and ideas for further research.

\section{Literature review}

As mentioned before, while the international literature is filled with studies into the effects of fiscal policy on macroeconomic outcomes, no consensus has been reached on the size (or sign) of government spending multipliers.

In one of the earliest studies on the impact of fiscal policy decisions using structural general equilibrium models, Baxter and King (1993) showed that in a simple real business cycle (RBC) model extended to include lump-sum taxes, an increase in government spending results in a negative wealth effect for households due to the associated increase in the discounted future value of taxes. This negative wealth effect, in turn, induces a positive labour supply response and an associated decrease in private consumption and a fall in real wages. New Keynesian models (which add both real and nominal frictions to the $\mathrm{RBC}$ framework) display the same wealth effect that induces a positive labour supply response and a 
fall in private consumption, although in this context real wages might increase as a result of increased demand for labour (Forni et al. 2009).

However, these theoretical correlations did not appear to match up with evidence from applied research. In order to reconcile the theoretical predictions with results from the empirical literature, recent studies in the DSGE literature have recognized the heterogeneity in consumer behaviour apparent in the data and moved away from the restrictive assumption of the representative, infinitely lived, rational agent. Mankiw (2000) argued that models that contain both Ricardian and non-Ricardian agents (that do not have access to financial markets and, as such, cannot save or borrow to augment consumption expenditure) are better suited for fiscal policy analysis. The seminal contribution by Galí et al. (2007) embedded rule-of-thumb (or non-Ricardian) agents in a standard monetary New Keynesian model. They found that the presence of these rule-of-thumb consumers, together with sticky prices and deficit financing, produces sizeable positive fiscal multipliers in the model economy.

Subsequent literature embedded this idea of rule-of-thumb consumers in the class of models of Smets and Wouters $(2005,2007)$ and Christiano et al. (2005). These models incorporate many of the features that have been shown to be useful in accounting for different aspects of the variation in macroeconomic aggregates, such as sticky prices, sticky wages, investment adjustment costs, habit persistence, etc. These richer models were shown to match the data reasonably well and could be used to generate estimates of the quantitative importance of rule-of-thumb consumers. Seminal examples of efforts in that direction can be found in the work of Coenen and Straub (2005), Erceg et al. (2006), Rabanal and López-Salido (2006), and Forni et al. (2009).

In contrast to Galí et al. (2007), Coenen and Straub (2005) found little evidence that government spending shocks crowd in consumption, mainly because the estimated share of rule-of-thumb consumers is relatively low for the eurozone - the estimated share of non-Ricardian households across their sample is significantly smaller than the mean of the prior which was set equal to 0.5 on the basis of micro-based estimates obtained for the pre-1990 period in the USA. In contrast, Erceg et al. (2006) found large, positive short-run fiscal multipliers associated with temporary increases in government spending. Similarly, Rabanal and López-Salido (2006) found that private consumption increases after a government spending shock when either non-separability in consumption-hours, non-Ricardian behaviour, or both are introduced into the model.

Most of the early literature focused on lump-sum taxes and aggregate government spending. Forni et al. (2009), among others, extended the framework of Christiano et al. (2005) and Galí et al. (2007) by including a detailed fiscal block. On the revenue side, the authors considered different distortionary tax rates, embedded in simple policy rules. On the expenditure side, they considered government consumption, excluding compensation for public employees (or government purchases of goods and services) and modelled public employment separately in order to gauge the differential impact of the different types of spending. They found that shocks to government purchases of goods and services and public sector compensation have small and temporary effects on macroeconomic aggregates, while shocks to transfers have a slightly larger and more permanent effect. The effects are more significant on the revenue side, with cuts in labour and consumption taxes inducing sizeable consumption and output responses, while reductions in capital taxes have a positive effect on private investment and total output in the medium run.

This highlights the importance of studying the underlying mix of government spending and tax decisions rather than just aggregate quantities. Mountford and Uhlig (2009) found substantial multipliers for the USA that are comparable to those of Blanchard and Perotti (2002), but emphasized that tax cuts are more effective in stimulating demand than increases in government spending as the private consumption response to government spending increases is insignificant. In a similar vein, Coenen et al. (2012) used a version of the European Central Bank's New Area-Wide Model extended to include a detailed 
specification of the fiscal sector and found that discretionary fiscal measures implemented during the Global Financial Crisis (GFC) increased annualized quarterly real GDP growth by up to 1.6 percentage points. However, the authors noted that a detailed modelling of the fiscal sector and the incorporation of several fiscal time series were pivotal for the result. Carvalho and Valli (2011) further distinguished between private and public capital accumulation and provide a mechanism through which public capital augments factor productivity in the private sector. This provides an additional avenue through which fiscal policy decisions can impact on real macroeconomic outcomes.

An alternative approach that seeks to mimic the positive wage and consumption responses often found in the empirical literature entails the introduction of a different habit formation process on the part of consumers. Ravn et al. (2010) developed a model of deep habits, which manages to produce positive consumption effects following a government spending impulse. ${ }^{1}$ Christoffel et al. (2011) introduced a specific form of habit formation in the composite of consumption and leisure (as in Jaccard 2010) in order to study their model's ability to generate a realistic bond premium, but at the same time find significant fiscal multipliers.

A further aspect of the policy response to the GFC that received little attention initially but has gained prominence recently is the fact that monetary and fiscal policy reacted jointly in an effort to stimulate demand. The interaction between monetary and fiscal policy is particularly important in an environment in which governments the world over contemplate when and how to normalize policy. This interaction has important implications for the size of the fiscal multiplier. Davig and Leeper (2011) estimated Markovswitching policy rules for the USA and found that monetary and fiscal policies fluctuate between active and passive states and that shocks to government spending induce positive consumption responses under certain policy regimes. In a follow-up paper, Leeper et al. (2015) found different-sized multipliers for the USA under different monetary-fiscal policy regimes. While output multipliers are comparable across regimes over the short run, in the long run multipliers are much larger under the passive monetary/active fiscal policy regime than under the active monetary/passive fiscal policy regime. Using a time-varying parameter vector autoregression (TVP-VAR), Jooste et al. (2013) found fiscal multipliers for South Africa that differ across time and between expansions and recessions. In fact, a common finding in the literature is that fiscal policy appears to be more effective during periods of economic downturn than during expansions (see Auerbach and Gorodnichenko 2012, 2014; Baum et al. 2012; Canzoneri et al. 2015; Owyang et al. 2013, among others).

Other studies have also investigated the impact of fiscal decisions when monetary policy is at (or close to) the zero nominal interest rate bound. Hall (2009) found that in an economy with an output multiplier of just under 1 in normal times, the multiplier can rise to 1.7 at a zero nominal interest rate, while Christiano et al. (2011) obtained an even stronger effect. Using a two-state Markov-switching framework, Eggertsson (2011) found that multipliers can be up to five times larger at the zero lower bound.

Several extensions have sought to enrich the basic model specifications in order to more closely resemble actual economies. One such extension is the inclusion of a mechanism for fiscal foresight on the model economy. According to Ramey (2011) and Leeper et al. (2012), models that do not explicitly account for foresight are mis-specified and biased responses. As shown by Jooste and Naraidoo (2017), fiscal foresight eliminates the results of Galí et al. (2007), in that a large share of rule-of-thumb consumers is not enough to generate positive co-movement between government spending and consumption. However, under certain calibrations, the inclusion of sticky wages still generates positive consumption responses and produces sizeable output multipliers.

\footnotetext{
${ }^{1}$ Deep habits imply that households form habits over sub-categories of consumption goods, such as cars and clothing, as opposed to aggregate consumption.
} 
The greater proportion of the literature on fiscal multipliers focuses on closed economies in the vein of Galí et al. (2007). While some studies have investigated the impact of fiscal policy decisions within the context of an open economy (e.g., Cavallo 2007; Erceg et al. 2006; Horvath and Marsal 2014; Levine et al. 2009; Ratto et al. 2007; Varthalitis 2019), this is much less prevalent. This aspect is particularly important in the context of the South African economy and given the assertion in the literature that fiscal multipliers are generally smaller in an open-economy setting.

Finally, despite the international interest in estimating the impact of fiscal shocks on macroeconomic outcomes, very little work has been done in the South African context. A notable exception is Jooste et al. (2013), who investigated the impact of fiscal policy shocks using three models: a medium-scale, closed-economy DSGE model; an open-economy structural vector error correction model (SVECM); and a TVP-VAR model. The use of these non-standard models allows the authors to answer some of the important questions raised in the field pertaining to the weaknesses of standard VARs (mentioned above). The authors found that increases in government expenditure have a positive effect on GDP in the short run (albeit less than unity in some instances), but that the impact becomes negligible in the long run. Similar results hold for changes to tax policy.

This paper adds to the burgeoning fiscal DSGE literature by extending the baseline closed-economy model to an open-economy setting, while at the same time including a more detailed fiscal sector and estimating key parameters.

\section{The model}

The small open-economy model structure closely follows that of Adolfson et al. (2007) and Christoffel et al. (2008), while incorporating a more active role for fiscal policy along the lines of Coenen et al. (2013). ${ }^{2}$

The basic open-economy structure is relatively standard: households consume both domestic and imported consumer goods, while optimizing agents can invest in domestic and foreign bonds. The optimizing households rent capital to firms and decide how much to invest each period, with changes to the rate of investment, as well as changes to the rate of capital utilization, subject to adjustment costs. Each household supplies a differentiated labour service to firms, allowing them to set their wage in a Calvo (1983) manner.

The model contains three types of firms: domestic producers, importers, and exporters. Domestic firms employ labour and capital in production. A differentiated good is produced by each type of firm. Prices are set following Calvo's (1983) model, but with a variation that allows for the indexation to past inflation (following Rabanal and López-Salido (2006)).

Finally, monetary policy follows a standard Taylor-type rule, while the foreign economy is assumed to be exogenous.

This basic specification is extended along the lines of Coenen et al. (2013) to include a more active role for fiscal policy. The specification of the fiscal sector balances the need for a high degree of detail, which is essential for analysing the quantitative effects of fiscal policy innovations, and tractability, which allows for the identification of the relevant transmission mechanisms. Specifically, the model includes (1) non-Ricardian (or rule-of-thumb) consumers to facilitate a direct transmission mechanism for government transfers; (2) government consumption that enters the households' utility function in a

\footnotetext{
${ }^{2}$ See Steinbach (2014) for an application of the Adolfson et al. (2007) model to South Africa.
} 
non-separable way; (3) public capital which can either be a complement or substitute for private capital, (4) time-varying distortionary taxes, and (5) a set of fiscal rules governing the endogenous response of fiscal variables.

\subsection{Households}

There is a continuum of households $h \in[0,1]$. They derive utility from consuming a basket of domestic consumption goods, both private and public, while they exhibit disutility in supplying labour services.

Following Coenen and Straub (2005), Galí et al. (2007), Jooste et al. (2013), and Coenen et al. (2013), among others, the household sector is divided into two distinct groups. A share $i \in(\omega, 1]$ of householdsreferred to as Ricardian households-invest, accumulate capital, and have access to both foreign and domestic financial markets, and display the standard optimizing behaviour. The remaining share $j \in[0, \omega]$ of households-referred to as non-Ricardian households-do not trade in assets and simply consume their after-tax disposable income. Importantly, Ricardian households can smooth consumption intertemporally in response to shocks, whereas non-Ricardian households simply consume their after-tax disposable income (Coenen et al. 2013).

Furthermore, it is assumed that valuable government consumption enters the households' utility function in a non-separable way. This feature has two important implications. First, under this specification, shocks to government consumption affect optimal private consumption decisions directly. This stands in contrast to the indirect wealth effect associated with separable government consumption. Second, the feature implies that it is theoretically possible to generate co-movements between private and government consumption, conditional on the estimated degree of complementarity.

Formally, aggregate consumption $\tilde{C}_{h, t}$ of household $h$ is defined as a constant elasticity of substitution (CES) aggregate:

$$
\tilde{C}_{h, t}=\left(\alpha_{G}^{\frac{1}{v_{G}}}\left(C_{h, t}\right)^{\frac{v_{G}-1}{v_{G}}}+\left(1-\alpha_{G}\right)^{\frac{1}{v_{G}}}\left(G_{t}\right)^{\frac{v_{G}-1}{v_{G}}}\right)^{\frac{v_{G}}{v_{G}-1}}
$$

where $C_{h, t}$ denotes the household's consumption of private goods and $G_{t}$ measures government consumption. $\alpha_{G}$ is a share parameter and $v_{G}$ measures the elasticity of substitution between private consumption and government consumption, with $v_{G}>0$. In particular, $v_{G} \rightarrow 0$ implies that private and public consumption are perfect complements, $v_{G} \rightarrow \infty$ results in perfect substitutability, and the CobbDouglas case is obtained when $v_{G} \rightarrow 1$.

\section{Ricardian households}

Lifetime utility of the $i$ th Ricardian household is a separable function in (aggregate) consumption and labour given by:

$$
E_{t} \sum_{k=0}^{\infty} \beta^{k}\left[\varepsilon_{t+k}^{c} \ln \left(\tilde{C}_{i, t+k}-\kappa \tilde{C}_{i, t+k-1}\right)-\varepsilon_{t+k}^{n} \frac{\left(N_{i, t+k}\right)^{1+\sigma_{L}}}{1+\sigma_{L}}\right]
$$

where $\beta$ denotes the discount factor, $\sigma_{L}$ is the inverse of the Frisch elasticity of labour supply, and $\kappa$ measures the degree of external habit formation. $\varepsilon_{t}^{c}$ is the consumption preference shock, while $\varepsilon_{t}^{n}$ represents a labour supply shock. These exogenous processes are assumed to evolve according to the following $\operatorname{AR}(1)$ specifications:

$$
\begin{aligned}
\hat{\varepsilon}_{t}^{c} & =\rho_{\varepsilon_{c}} \hat{\varepsilon}_{t-1}^{c}+\varepsilon_{t}^{c} & & \varepsilon_{t}^{c} \sim \mathscr{N}\left(0, \sigma_{c}\right) \\
\hat{\varepsilon}_{t}^{n} & =\rho_{\varepsilon_{n}} \hat{\varepsilon}_{t-1}^{n}+\varepsilon_{t}^{n} & & \varepsilon_{t}^{n} \sim \mathscr{N}\left(0, \sigma_{n}\right)
\end{aligned}
$$

where $E\left(\hat{\varepsilon}_{t}^{i}\right)=1$ and $\hat{\varepsilon}_{t}^{i}=\left(\varepsilon_{t}^{i}-1\right) / 1$ for $i \in\{c, n\}$. Throughout the paper, a variable with a hat denotes a log-linearized variable: $\hat{X}_{t}=\frac{X_{t}-X}{X}$. 
Budget constraint. The representative Ricardian household optimizes the utility function in Equation (2) subject to the following budget constraint:

$$
\begin{aligned}
\left(1+\tau_{t}^{c}\right) P_{C, t} C_{i, t}+ & P_{I, t} I_{i, t}+\frac{B_{i, t+1}}{\varepsilon_{t}^{R P} R_{t}}+\frac{S_{t} B_{i, t+1}^{*}}{\left[1-\Gamma_{B^{*}}\left(s_{B^{*}, t+1} ; \varepsilon_{t}^{R P^{*}}\right)\right] R_{t}^{*}} \\
=\left(1-\tau_{t}^{w}\right) W_{i, t} N_{i, t}+\left(1-\tau_{t}^{k}\right)\left[R_{K, t} u_{i, t}-\Gamma_{u}\left(u_{i, t}\right) P_{I, t}\right] K_{i, t}+\tau_{t}^{k} \delta_{t} P_{I, t} K_{i, t} & +D_{i, t}+T R_{i, t}+B_{i, t}+S_{t} B_{i, t}^{*}+\Xi_{i, t}^{B}+\Xi_{i, t}^{B^{*}}
\end{aligned}
$$

where $P_{C, t}$ and $P_{I, t}$ are the unit prices of the private consumption and investment good, respectively. (1 $\left.\tau_{t}^{w}\right) W_{i, t} N_{i, t}$ is net labour income, $\left(1-\tau_{t}^{k}\right) R_{K, t} u_{t} K_{i, t}$ is net nominal income from renting capital services $K_{i, t}^{s}=K_{i, t} u_{t}$ to firms at the rate $R_{K, t}$, and $D_{i, t}$ are profits distributed by firms to Ricardians (by assumption the only owners of firms). $R_{t}$ and $R_{t}^{*}$ denote the respective risk-free returns on domestic and foreign government bonds. Foreign government bonds are denominated in foreign currency and, therefore, are converted to domestic currency units using the nominal exchange rate $S_{t}$ (expressed in terms of units of domestic currency per unit of foreign currency).

The fiscal authority finances its expenditures by issuing one period nominal bonds $B_{i, t}$ and by levying taxes on labour income $\left(\tau_{t}^{w}\right)$, capital income $\left(\tau_{t}^{k}\right)$, and consumption $\left(\tau_{t}^{c}\right)$. As in Coenen et al. (2013), it is assumed that the utilization cost of capital and capital depreciation, $\delta_{t} P_{I, t} K_{i, t}$, is exempt from taxation.

The expenditure side features the amount of government bonds (both foreign and domestic) that Ricardian households carry over from the previous period, discounted by the nominal interest rate. However, the effective return on risk-free domestic bonds depends on a financial intermediation premium, represented by the exogenous 'risk premium' shock $\varepsilon_{t}^{R P}$, which drives a wedge between the policy interest rate and the return required by the household. Similarly, following Christoffel et al. (2008), the household encounters an external financial intermediation premium $\Gamma_{B^{*}}\left(B_{t+1}^{*} ; \varepsilon_{t}^{R P^{*}}\right)$ when taking a position in the international bond market. This premium depends on the economy-wide holdings of foreign bonds expressed in domestic currency units relative to domestic nominal output, $s_{B^{*}, t+1}=S_{t} B_{t+1}^{*} / P_{Y, t} Y_{t}$, and takes the form:

$$
\Gamma_{B^{*}}\left(s_{B^{*}, t+1} ; \varepsilon_{t}^{R P^{*}}\right)=\gamma_{B^{*}}\left(\left(\varepsilon_{t}^{R P^{*}}\right)^{\frac{1}{\gamma_{B^{*}}}} \exp \left(\frac{S_{t} B_{t+1}^{*}}{P_{Y, t} Y_{t}}\right)-1\right)
$$

with $\gamma_{B^{*}}>0$. That is, if the domestic economy is a net debtor, households have to pay a higher external intermediation premium when investing in foreign capital markets. The shock $\varepsilon_{t}^{R P^{*}}$ represents the exogenous component of the external intermediation premium and is referred to as the external risk premium shock. The incurred intermediation premia are rebated in the form of lump-sum payments, $\Xi_{i, t}^{B}$ and $\Xi_{i, t}^{B^{*}}$.

Finally, adjustment costs are introduced on the households choice of capacity utilization $u_{i, t}$. This cost is incurred if the level of capital utilization deviates from its steady-state value of 1 . The cost is described by an increasing convex function $\Gamma_{u}\left(u_{i, t}\right)$, with $\Gamma_{u}(1)=0$. Hence $\Gamma_{u}\left(u_{i, t}\right) P_{t} K_{i, t}$ denotes the cost associated with the utilization level $u_{i, t}$.

The adjustment cost takes the following functional form:

$$
\Gamma_{u}\left(u_{i, t}\right)=\gamma_{u, 1}\left(u_{i, t}-1\right)+\frac{\gamma_{u, 2}}{2}\left(u_{i, t}-1\right)^{2}
$$

with $\gamma_{u, 1}, \gamma_{u, 2}>0$.

Capital and investment. The physical capital stock owned by household $i$ evolves according to the following capital accumulation equation:

$$
K_{i, t+1}=(1-\delta) K_{i, t}+\varepsilon_{t}^{i}\left(1-\Gamma_{I}\left(I_{i, t} / I_{i, t-1}\right)\right) I_{i, t}
$$


where $\delta$ is the depreciation rate, $\Gamma_{I}\left(I_{i, t} / I_{i, t-1}\right)$ represents an adjustment cost function, and $\varepsilon_{t}^{i}$ is an investment-specific technology shock. This shock follows the AR(1) process

$$
\hat{\varepsilon}_{t}^{i}=\rho_{c} \hat{\varepsilon}_{t-1}^{i}+\varepsilon_{t}^{i} \quad \varepsilon_{t}^{i} \sim \mathcal{N}\left(0, \sigma_{i}\right)
$$

with $E\left[\varepsilon_{t}^{i}\right]=1$ and $\hat{\varepsilon}_{t}^{i}=\left(\varepsilon_{t}^{i}-1\right) / 1$.

Following Christoffel et al. (2008), the investment adjustment cost function, formulated as a function of the rate of change in gross private investment, takes the form:

$$
\Gamma_{I}\left(I_{i, t} / I_{i, t-1}\right)=\frac{\gamma_{I}}{2}\left(\frac{I_{i, t}}{I_{i, t-1}}-g_{z}\right)^{2}
$$

with $\gamma_{I}>0$ and where $g_{z}$ denotes the economy's trend growth rate in the non-stochastic steady state.

First-order conditions. Taking all fiscal variables and prices, including wages, as given and defining $\Lambda_{i, t} / P_{t}$ and $\Lambda_{i, t} Q_{i, t}$ as the Lagrange multipliers associated with the budget constraint (Equation (3)) and the capital accumulation Equation (6) respectively, optimization of the household's utility function yields the following first-order conditions with respect to $\left\{C_{i, t}, I_{i, t}, K_{i, t+1}, u_{i, t}, B_{i, t+1}, B_{i, t+1}^{*}\right\}:$ Consumption, $C_{i, t}$

$$
\Lambda_{i, t}=\alpha_{G}^{\frac{1}{v_{G}}} \varepsilon_{t}^{c} \frac{\left(\tilde{C}_{i, t}-\kappa \tilde{C}_{i, t-1}\right)^{-1}}{1+\tau_{t}^{c}}\left(\frac{\tilde{C}_{i, t}}{C_{i, t}}\right)^{\frac{1}{v_{G}}}
$$

Investment, $I_{i, t}$

$$
\begin{array}{r}
\frac{P_{I, t}}{P_{C, t}}=Q_{i, t} \varepsilon_{t}^{i}\left[1-\Gamma_{I}\left(\frac{I_{i, t}}{I_{i, t-1}}\right)-\Gamma_{I}^{\prime}\left(\frac{I_{i, t}}{I_{i, t-1}}\right) \frac{I_{i, t}}{I_{i, t-1}}\right] \\
+\beta E_{t}\left[\frac{\Lambda_{i, t+1}}{\Lambda_{i, t}} Q_{i, t+1} \varepsilon_{t+1}^{i} \Gamma_{I}^{\prime}\left(\frac{I_{i, t+1}}{I_{i, t}}\right) \frac{I_{i, t+1}^{2}}{I_{i, t}^{2}}\right]
\end{array}
$$

Capital stock, $k_{t+1}$

$$
\begin{array}{r}
Q_{i, t}=\beta E_{t}\left[\frac { \Lambda _ { i , t + 1 } } { \Lambda _ { i , t } } \left((1-\delta) Q_{i, t+1}+\left(1-\tau_{t+1}^{k}\right) \frac{R_{K, t+1}}{P_{C, t+1}} u_{i, t+1}\right.\right. \\
\left.\left.+\left(\tau_{t+1}^{k} \delta-\left(1-\tau_{t+1}^{k}\right) \Gamma_{u}\left(u_{i, t+1}\right)\right) \frac{P_{I, t+1}}{P_{C, t+1}}\right)\right]
\end{array}
$$

Capital utilization, $u_{t}$

$$
R_{K, t}=\Gamma_{u}^{\prime}\left(u_{i, t}\right) P_{I, t}
$$

Domestic bond holdings, $B_{i, t+1}$

$$
\beta \varepsilon_{t}^{R P} R_{t} E_{t}\left[\frac{\Lambda_{i, t+1}}{\Lambda_{i, t}} \frac{P_{C, t}}{P_{C, t+1}}\right]=1
$$

Foreign bond holdings, $B_{i, t+1}^{*}$

$$
\beta\left(1-\Gamma_{B^{*}}\left(s_{B^{*}, t+1} ; \varepsilon_{t}^{R P^{*}}\right)\right) R_{t}^{*} E_{t}\left[\frac{\Lambda_{i, t+1}}{\Lambda_{i, t}} \frac{P_{C, t}}{P_{C, t+1}} \frac{S_{t+1}}{S_{t}}\right]=1
$$

Here, $\Lambda_{i, t}$ represents the shadow price of a unit of consumption good-that is, the marginal utility of consumption out of income. Similarly, $Q_{i, t}$ measures the shadow price of a unit of investment goodthat is, Tobin's Q. ${ }^{3}$

\footnotetext{
${ }^{3}$ As noted by Christoffel et al. (2008), the domestic risk premium shock, $\varepsilon_{t}^{R P}$, affects investment via Tobin's Q and helps to explain the co-movement of consumption and investment observed in the data. In contrast, the consumption preference shock, $\varepsilon_{t}^{c}$, moves consumption and investment in opposite directions.
} 
In equilibrium, with all households choosing identical allocations, the combination of Equations (12) and (13) yields the risk-adjusted uncovered interest parity (UIP) condition, reflecting the assumption that the return on foreign bonds is subject to an external financial intermediation premium.

\section{Non-Ricardian households}

Non-Ricardian households face the same utility function as Ricardian households. However, they do not display the standard optimizing behaviour, cannot invest in physical capital, and do not have access to financial markets. As a result, each non-Ricardian household $j \in[0, \omega]$ simply consumes its disposable income, comprising after-tax disposable income and government transfers, in each period. The periodby-period budget constraint is:

$$
\left(1+\tau_{t}^{c}\right) P_{C, t} C_{j, t}=\left(1-\tau_{t}^{w}\right) W_{j, t} N_{j, t}+T R_{j, t}
$$

Following Coenen et al. (2013), a possibly uneven distribution of government transfers among Ricardian and non-Ricardian households is allowed according to:

$$
\bar{\omega}\left(T R_{i, t} / T R_{i}-1\right)=(1-\bar{\omega})\left(T R_{j, t} / T R_{j}-1\right)
$$

\section{Labour market and wages}

Each household $h$ supplies its differentiated labour services $N_{h, t}$ in monopolistically competitive markets. It is assumed that the labour force of all households is uniformly distributed among the differentiated firms, and that employers cannot distinguish between different labour types. Furthermore, following Adolfson et al. (2007), Christoffel et al. (2008), and Coenen et al. (2013), among others, wage adjustments are sluggish due to the presence of staggered wage contracts, modelled as a Calvo (1983) process.

Note that, by assumption, non-Ricardians do not display intertemporal optimizing behaviour. Following Erceg et al. (2006) and Forni et al. (2009), it is assumed that the non-Ricardian wage rate equals the average of the Ricardians. Since all households face the same labour demand schedule in the private sector, this implies that both the wage rate and hours worked will be equal for every agent in the economy.

Following Calvo (1983), the representative Ricardian household $i$ optimally resets its nominal wage contract $W_{i, t}$ in a given period $t$ with probability $1-\theta_{w}$. All households that are allowed to reset their wage contracts choose the same wage rate, $\widetilde{W}_{t}=\widetilde{W}_{i, t}$. Those households that do not reset their wage adjust their wage contracts to reflect developments in underlying productivity and inflation:

$$
W_{i, t}=g_{z, t} \Pi_{C, t}^{\dagger} W_{i, t-1}
$$

where $g_{z, t}$ represents the underlying rate of productivity growth and $\Pi_{C, t}^{\dagger}=\left(\pi_{C, t-1}\right)^{\chi_{W}}\left(\bar{\pi}_{C, t}\right)^{1-\chi_{W}}$ is a geometric average of past consumer price inflation $\pi_{C, t-1}=P_{C, t-1} / P_{C, t-2}$ and the monetary authority's possibly time-varying inflation objective, $\bar{\pi}_{C, t}$. The indexation parameter $\chi_{W}$ determines the weight attached to past inflation.

The representative Ricardian household that reset its wage contract in period $t$ maximizes lifetime utility (given by Equation (2)) subject to the budget constraint (Equation (3)), the demand for its differentiated labour services, and the wage-indexation scheme (Equation (15)).

Using the fact that in equilibrium all households choose the same optimal reset wage $\widetilde{W}_{t}$, the optimization results in the following first-order condition characterizing the representative Ricardian household's 
optimal wage-setting decision:

$$
E_{t}\left[\sum_{k=0}^{\infty}\left(\theta_{W} \beta\right)^{k}\left(\Lambda_{t+k}\left(1-\tau_{t+k}^{w}\right) g_{z ; t, t+k} \frac{\Pi_{C ; t, t+k}^{\dagger}}{\Pi_{C ; t, t+k}} \frac{\widetilde{W}_{t}}{P_{C, t}}-\phi_{t+k}^{W} \varepsilon_{t+k}^{n}\left(N_{i, t+k}\right)^{\sigma_{L}}\right) N_{i, t+k}\right]=0
$$

where $\Lambda_{t+k}$ denotes the marginal utility out of income, $g_{z ; t, t+k}=\prod_{s=1}^{k} g_{z, t+s}, \prod_{C ; t, t+k}^{\dagger}=\prod_{s=1}^{k}\left(\pi_{C, t-1}\right)^{\chi_{W}}$ $\left(\bar{\pi}_{C, t}\right)^{1-\chi_{W}}$, and $\Pi_{C ; t, t+k}=\prod_{s=1}^{k} \pi_{C, t+s-1}$.

As noted by Christoffel et al. (2008), this expression implies that in those labour markets in which wage contracts are re-optimized, optimal wage rates are set so as to equate the households' discounted sum of expected after-tax marginal revenues, expressed in consumption-based utility terms, $\Lambda_{t+k}$, to the discounted sum of expected marginal cost, expressed in terms of marginal disutility of labour, $\Delta_{i, t+k}=$ $-N_{i, t+k}^{\sigma_{L}}$. In the absence of wage staggering $\xi_{w}=0, \phi_{t}^{W}$ represents the time-varying markup of the real after-tax wage over households' marginal rate of substitution between consumption and leisure:

$$
\left(1-\tau_{t}^{w}\right) \frac{\tilde{W}_{t}}{P_{C, t}}=-\phi_{t}^{W} \varepsilon_{t}^{n} \frac{\Delta_{t}}{\Lambda_{t}}
$$

reflecting the existence of monopoly power on the part of households. ${ }^{4}$

Aggregate wage dynamics. As mentioned above, it is assumed that the non-Ricardian wage rate simply equals the average of the Ricardians. ${ }^{5}$ Since all households face the same labour demand schedule in the private sector, this assumption implies that both the wage rate and hours worked will be equal for every agent in the economy. In other words, the common economy-wide wage rate, $W_{i, t}=W_{j, t}\left(=W_{h, t}\right)=W_{t}$, and identical labour demand curves imply that Ricardian and non-Ricardian households supply the same amount of labour-that is, $N_{i, t}=N_{j, t}\left(=N_{h, t}\right)=N_{t}$.

Furthermore, with the continuum of households setting wage contracts on the basis of Equations (15) and (16), the aggregate wage index $W_{t}$ evolves according to:

$$
W_{t}=\left(\theta_{W}\left(g_{z, t} \Pi_{C, t}^{\dagger} W_{t-1}\right)^{\frac{1}{1-\phi_{t}^{W}}}+\left(1-\theta_{W}\right)\left(\widetilde{W}_{t}\right)^{\frac{1}{1-\phi_{t}^{W}}}\right)^{1-\phi_{t}^{W}}
$$

\subsection{Production}

The structure closely follows that of Christoffel et al. (2008) and Coenen et al. (2013). There are two types of monopolistically competitive intermediate-good firms: a continuum of domestic intermediategood firms indexed by $f \in[0,1]$ producing differentiated goods that are sold both domestically and abroad, and a continuum of foreign intermediate-good firms indexed by $f^{*} \in[0,1]$ producing goods for the domestic market. Additionally, there is a set of four representative domestic final-good firms that combine the differentiated domestic and foreign intermediate goods into four distinct non-tradeable goods, namely a private consumption good, a public consumption good, a private investment good, and a public investment good.

\footnotetext{
${ }^{4}$ Using the fact that, in equilibrium, the marginal disutility is equal across households: $\Delta_{i, t}=\Delta_{t}$.

${ }^{5}$ This is a simplifying assumption. Non-Ricardians appear in the model because of credit market imperfections (i.e. they cannot borrow and save to smooth their consumption). This also implies that these individuals might be lower-income workers with no collateral. As such, their wage rates might be different to, and indeed lower than, the wage rates of Ricardians. Several authors, including Forni et al. (2009) (using a similar model set-up to the one discussed here), check a more general version of the labour market, able to recognize a role for non-Ricardian preferences in labour choices even if they cannot optimize intertemporally. The authors find no substantial difference between the results of the simple specification and the more complex approach, and find that it is indeed the assumed share of non-Ricardian households that is important from a model dynamic perspective. As such, the assumption of equal wage rates is maintained in the subsequent analysis.
} 


\section{Domestic intermediate-good firms}

Production. The intermediate good-producing firms operate in a monopolistically competitive environment and produce differentiated goods according to the following production technology:

$$
Y_{f, t}=\varepsilon_{t}\left(\tilde{K}_{f, t}\right)^{\alpha}\left(z_{t} N_{f, t}\right)^{1-\alpha}-z_{t} \psi
$$

where $z_{t}$ is a permanent technology shock, $\varepsilon_{t}$ is a temporary (covariance stationary) technology shock, $\tilde{K}_{f, t}$ is physical capital services, and $N_{f, t}$ denotes the homogeneous labour input hired by firm $f$ :

$$
N_{f, t}=\left(\int_{0}^{1}\left(N_{f, t}^{h}\right)^{\frac{1}{\phi_{t}^{W}}} d h\right)^{\phi_{t}^{W}}
$$

As discussed above, the parameter $\phi_{t}^{W}$ has a natural interpretation as a markup in the household-specific labour market.

The introduction of a fixed cost, $z_{t} \psi$, ensures zero steady-state firm profits. It is assumed that the growth in fixed cost is equal to the steady-state growth rate in underlying productivity. ${ }^{6}$

As before, the stationary technology shock has the following presentation:

$$
\hat{\varepsilon}_{t}=\rho_{\varepsilon} \hat{\varepsilon}_{t-1}+\varepsilon_{t}^{\varepsilon} \quad \varepsilon_{t}^{\varepsilon} \sim \mathscr{N}\left(0, \sigma_{\varepsilon}\right)
$$

where $E\left(\varepsilon_{t}\right)=1$ and $\hat{\varepsilon}_{t}=\left(\varepsilon_{t}-1\right) / 1$.

The process for the permanent technology shock, $z_{t}$, in Equation (19) is given by:

$$
\frac{z_{t}}{z_{t-1}}=g_{z, t}=\left(1-\rho_{g_{z}}\right) g_{z}+\rho_{g_{z}} g_{z, t-1}+\varepsilon_{g_{z}, t} \quad \varepsilon_{g_{z}, t} \sim \mathscr{N}\left(0, \sigma_{g_{z}}\right)
$$

where $g_{z}$ is the steady-state growth rate of technology. Fixed costs are scaled by $z_{t}$ to guarantee that share of fixed costs with respect to output does not vanish as output grows. Following Coenen et al. (2013), the production function (Equation (19)) is augmented with public capital in the presence of a well-specified government sector (which invests in public capital). Physical capital used in production is a CES aggregate of private capital services $K_{f, t}^{s}$ and the public capital stock $K_{G, t}$ :

$$
\tilde{K}_{f, t}=\left(\alpha_{K}^{\frac{1}{v_{K}}}\left(K_{f, t}^{s}\right)^{\frac{v_{K}-1}{v_{K}}}+\left(1-\alpha_{K}\right)^{\frac{1}{v_{K}}}\left(K_{G, t}\right)^{\frac{v_{K}-1}{v_{K}}}\right)^{\frac{v_{K}}{v_{K}-1}}
$$

where $\alpha_{K}$ is a share parameter and, analogous to the CES consumption aggregate, the parameter $v_{K}>0$ governs the elasticity of substitution between private capital services and the public capital stock. $v_{K} \rightarrow 0$ implies private capital services and public capital are perfect complements, $v_{K} \rightarrow \infty$ implies they are perfect substitutes, and $v_{K} \rightarrow 1$ yields the Cobb-Douglas case. The law of motion for public capital is analogous to that for private capital formation (Equation (6)):

$$
K_{G, t+1}=\left(1-\delta_{G}\right) K_{G, t}+\varepsilon_{t}^{i}\left(1-\Gamma_{G}\left(I_{G, t} / I_{G, t-1}\right)\right) I_{G, t}
$$

where $\Gamma_{G}$ takes the same form as in Equation (7).

Importantly, each intermediate-good firm $f$ has access to the same public capital stock. Additionally, the stock of public capital is assumed to grow at the same speed as private capital services along the balanced growth path of the model. Public capital augments private production at no direct cost for

\footnotetext{
${ }^{6}$ The parameter $\psi$ is calibrated to ensure zero profits in steady state. The zero profit condition guarantees that, in equilibrium, there is no incentive for other firms to enter the market.
} 
the firm and can in this case be interpreted as an externality to the private productive sector. Financing of public capital is not factored into the cost accounting of firms as it takes place through the general tax system. Finally, note that $K_{t}^{s}$ might differ from the physical private capital stock in the presence of variable capital utilization, $u_{t}$ - that is, $K_{t}^{s}=u_{t} K_{t}$.

The intermediate-good firm rents private capital services at a gross nominal rate $R_{K, t}$ and compensates the homogeneous labour service at the nominal wage rate $W_{t}$. Defining $M C_{f, t}$ as the Lagrange multiplier associated with the technology constraint (Equation (19)) (i.e. nominal marginal cost), the firm's cost minimization problem is as follows:

$$
\min _{K_{f, t}^{s}, N_{f, t}} W_{t} N_{f, t}+R_{K, t} K_{f, t}^{s}+M C_{f, t}\left[Y_{f, t}-\varepsilon_{t}\left(\tilde{K}_{f, t}\right)^{\alpha}\left(z_{t} N_{f, t}\right)^{1-\alpha}+z_{t} \psi\right]
$$

Optimization with respect to $K_{f, t}^{s}$ and $N_{f, t}$ yields the following first-order conditions:

$$
R_{K, t}=\alpha \frac{Y_{f, t}+z_{t} \psi}{K_{f, t}^{s}}\left[1+\left(\frac{1-\alpha_{K}}{\alpha_{K}}\right)^{\frac{1}{v_{K}}}\left(\frac{K_{G, t}}{K_{f, t}^{s}}\right)^{\frac{v_{K}-1}{v_{K}}}\right]^{-1} M C_{f, t}
$$

and

$$
W_{t}=(1-\alpha) \frac{Y_{f, t}+z_{t} \psi}{N_{f, t}} M C_{f, t}
$$

or, more compactly,

$$
\frac{R_{K, t}}{W_{t}}=\frac{\alpha}{1-\alpha} \frac{N_{f, t}}{K_{f, t}^{s}}\left[1+\left(\frac{1-\alpha_{K}}{\alpha_{K}}\right)^{\frac{1}{v_{K}}}\left(\frac{K_{G, t}}{K_{f, t}^{s}}\right)^{\frac{v_{K}-1}{v_{K}}}\right]^{-1}
$$

Since all firms $f$ face the same input prices and since they all have access to the same production technology, nominal marginal costs $M C_{f, t}$ are identical across firms-that is, $M C_{f, t}=M C_{t}$ with

$$
M C_{t}=\frac{1}{\varepsilon_{t} z_{t}^{1-\alpha} \alpha^{\alpha}(1-\alpha)^{1-\alpha}}\left(R_{K, t}\right)^{\alpha}\left(W_{t}\right)^{1-\alpha}\left(\frac{K_{t}^{s}}{\tilde{K}_{t}}\right)^{\alpha}\left[1+\left(\frac{1-\alpha_{K}}{\alpha_{K}}\right)^{\frac{1}{v_{K}}}\left(\frac{K_{G, t}}{K_{t}^{s}}\right)^{\frac{v_{K}-1}{v_{K}}}\right]^{\alpha}
$$

As discussed above, the nominal wage contract $W_{h, t}$ for the differentiated labour services of household $h$ is set in monopolistically competitive markets. This implies that firm $f$ takes $W_{h, t}$ as given and chooses the optimal labour input by minimizing the total wage-related labour cost, $\int_{0}^{1} W_{h, t} N_{f, t}^{h} d h$, subject to the aggregation constraint (Equation (20)).

As a result, the demand for labour variety $h$ is a function of the ratio of household-specific wage rate $W_{h, t}$ to the aggregate wage index $W_{t}$ :

$$
N_{f, t}^{h}=\left(\frac{W_{h, t}}{W_{t}}\right)^{-\frac{\phi_{t}^{W}}{\phi_{t}^{W}-1}} N_{f, t}
$$

with $\phi_{t}^{W} /\left(\phi_{t}^{W}-1\right)$ representing the wage elasticity of labour demand.

The wage index $W_{t}$ can be obtained by substituting the labour index (Equation (20)) into the labour demand schedule (Equation (30)) and then aggregating across households:

$$
W_{t}=\left(\int_{0}^{1} W_{h, t}^{\frac{1}{1-\phi_{t}^{W}}} d h\right)^{1-\phi_{t}^{W}}
$$


Aggregating over the continuum of firms delivers the aggregate demand for the labour services of household $h$ :

$$
N_{t}^{h}=\int_{0}^{1} N_{f, t}^{h} d f=\left(\frac{W_{h, t}}{W_{t}}\right)^{-\frac{\phi_{t}^{W}}{\phi_{t}^{W}-1}} N_{t}
$$

Price setting. Each intermediate goods producer $f$ sells its output $Y_{f, t}$ in both the domestic and foreign market under monopolistic competition. As in Christoffel et al. (2008) and Coenen et al. (2013), it is assumed that the firm charges different prices at home and abroad, setting prices in producer currency regardless of the destination market. Firm $f$ sets prices in a staggered manner as proposed by Calvo (1983). Each intermediate firm optimally resets prices in a given period $t$ either with probability $\left(1-\theta_{H}\right)$ or $\left(1-\theta_{X}\right)$, depending on whether it sells its differentiated output at home or abroad.

Defining $P_{H, f, t}$ as the domestic price of good $f$ and $P_{X, f, t}$ its foreign price, all firms that can optimize choose the same price: $\tilde{P}_{H, f, t}=\tilde{P}_{H, t}$ and $\tilde{P}_{X, f, t}=\tilde{P}_{X, t}$. Following Adolfson et al. (2007), Christoffel et al. (2008), and Du Plessis et al. (2014), among others, it is assumed that firms that are unable to re-optimize will index their price to past inflation and the monetary authority's current inflation target:

$$
\begin{aligned}
P_{H, f, t} & =\left(\pi_{H, t-1}\right)^{\chi_{H}}\left(\bar{\pi}_{C, t}\right)^{1-\chi_{H}} P_{H, f, t-1} \\
P_{X, f, t} & =\left(\pi_{X, t-1}\right)^{\chi_{X}}\left(\bar{\pi}_{C, t}\right)^{1-\chi_{X}} P_{X, f, t-1}
\end{aligned}
$$

where $\pi_{H, t-1}=P_{H, t-1} / P_{H, t-2}, \pi_{X, t-1}=P_{X, t-1} / P_{X, t-2}, \bar{\pi}_{C, t}$ is the possibly time-varying inflation objective of the domestic monetary authority (in terms of consumer prices), and $\chi_{H}$ and $\chi_{X}$ are indexation parameters. The time-varying inflation target is analogous to a flexible inflation targeting regime. Following Steinbach (2014) and as discussed in Section 4.2, its role in the model is to facilitate the transition from the high inflation and interest rates prevalent in the 1990s to the low inflation and interest rate environment thereafter.

Each firm $f$ that optimally resets its price in period $t$ maximizes the discounted sum of its expected nominal profits,

$$
E_{t}=\left[\sum_{k=0}^{\infty} \lambda_{t, t+k}\left(\theta_{H}^{k} D_{H, f, t+k}+\theta_{X}^{k} D_{X, f, t+k}\right)\right]
$$

subject to the price indexation schemes (33) and (34), taking as given demand for its differentiated output, $H_{f, t}$ and $X_{f, t}$ (derived below). The stochastic discount factor $\lambda_{t, t+k}$ can be obtained from the consumption Euler equation of the households, while

$$
\begin{gathered}
D_{H, f, t+k}=P_{H, f, t} H_{f, t}-M C_{t} H_{f, t} \\
D_{X, f, t+k}=P_{X, f, t} X_{f, t}-M C_{t} X_{f, t}
\end{gathered}
$$

are period- $t$ nominal profits (net of fixed costs), which are distributed to the households.

The optimization problem in the following first-order condition characterizing the firm's optimal pricing decision:

$$
E_{t}\left[\sum_{k=0}^{\infty} \lambda_{t, t+k} \theta_{H}^{k}\left(\Pi_{H, t, t+k}^{\dagger} \tilde{P}_{H, t}-\phi_{t+k}^{H} M C_{t+k}\right) H_{f, t+k}\right]=0
$$

where we have substituted the indexation scheme (Equation (33)), noting that $P_{H, f, t+k}=\Pi_{H, t, t+k}^{\dagger} \tilde{P}_{H, t}$ with $\Pi_{H, t, t+k}^{\dagger}=\prod_{s=1}^{k}\left(\pi_{H, t+s-1}\right)^{\chi_{H}}\left(\bar{\pi}_{t+s}\right)^{1-\chi_{H}}$.

The expression in (Equation (38)) states that in those markets where price contracts are re-optimized, the optimal price is chosen so as to equate the firm's discounted sum of expected revenues to the discounted sum of expected marginal cost. In the absence of price staggering $\left(\theta_{H}=0\right)$, the factor $\phi_{t}^{H}$ represents a 
possibly time-varying markup of price over nominal marginal cost, reflecting the degree of monopoly power on the part of the intermediate-good firm.

With the continuum of intermediate-good firms setting the prices for their differentiated products sold domestically according to Equations (33) and (38), the aggregate price index $P_{H, t}$ evolves according to:

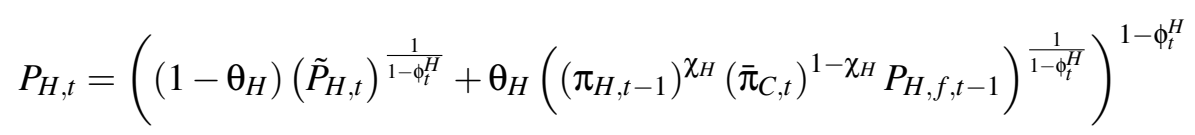

Similarly, the following first-order condition for the firm's optimal pricing decision for its output sold in the foreign market is given by:

$$
E_{t}\left[\sum_{k=0}^{\infty} \lambda_{t, t+k} \theta_{X}^{k}\left(\Pi_{X, t, t+k}^{\dagger} \tilde{P}_{X, t}-\phi_{t+k}^{X} M C_{t+k}\right) X_{f, t+k}\right]=0
$$

The aggregate price index set for the differentiated products sold abroad is given by:

$$
P_{X, t}=\left(\left(1-\theta_{X}\right)\left(\tilde{P}_{X, t}\right)^{\frac{1}{1-\phi_{t}^{X}}}+\theta_{X}\left(\left(\pi_{X, t-1}\right)^{\chi_{X}}\left(\bar{\pi}_{C, t}\right)^{1-\chi_{X}} P_{X, f, t-1}\right)^{\frac{1}{1-\phi_{t}^{X}}}\right)^{1-\phi_{t}^{X}}
$$

Combining the log-linearized versions of Equations (38) and (40) with the log-linearized versions of the aggregate price indices, the following expressions for the log-linear versions of the domestic and export price Phillips curve relations are obtained:

$$
\begin{aligned}
\left(\hat{\pi}_{H, t}-\hat{\bar{\pi}}_{C, t}\right)= & \frac{\beta}{1+\beta \chi_{H}} E_{t}\left[\hat{\pi}_{H, t+1}-\hat{\bar{\pi}}_{C, t+1}\right]+\frac{\chi_{H}}{1+\beta \chi_{H}}\left(\hat{\pi}_{H, t-1}-\hat{\bar{\pi}}_{C, t}\right) \\
& +\frac{\beta \chi_{H}}{1+\beta \chi_{H}} E_{t}\left[\hat{\bar{\pi}}_{C, t+1}-\hat{\bar{\pi}}_{C, t}\right]+\frac{\left(1-\beta \theta_{H}\right)\left(1-\theta_{H}\right)}{\theta_{H}\left(1+\beta \chi_{H}\right)}\left(\widehat{m c}_{t}^{H}+\hat{\phi}_{t}^{H}\right) \\
\left(\hat{\pi}_{X, t}-\hat{\bar{\pi}}_{C, t}\right)= & \frac{\beta}{1+\beta \chi_{X}} E_{t}\left[\hat{\pi}_{X, t+1}-\hat{\bar{\pi}}_{C, t+1}\right]+\frac{\chi_{X}}{1+\beta \chi_{X}}\left(\hat{\pi}_{X, t-1}-\hat{\bar{\pi}}_{C, t}\right) \\
& +\frac{\beta \chi_{X}}{1+\beta \chi_{X}} E_{t}\left[\hat{\bar{\pi}}_{C, t+1}-\hat{\bar{\pi}}_{C, t}\right]+\frac{\left(1-\beta \theta_{X}\right)\left(1-\theta_{X}\right)}{\theta_{X}\left(1+\beta \chi_{X}\right)}\left(\widehat{m c}_{t}^{X}+\hat{\phi}_{t}^{X}\right)
\end{aligned}
$$

where $\widehat{m c}_{t}^{H}=\widehat{m c}_{t}-\hat{p}_{H, t}$ and $\widehat{m c}_{t}^{X}=\widehat{m c}_{t}-\hat{p}_{X, t}$ represents average real marginal costs for the domestic intermediate-good firm selling in the domestic and foreign markets respectively (expressed as the logdeviation from the steady state), with $m c_{t}=M C_{t} / P_{C, t}, p_{H, t}=P_{H, t} / P_{C, t}$ and $p_{X, t}=P_{X, t} / P_{C, t}$.

\section{Foreign intermediate-good firms}

Each foreign intermediate-goods producer $f^{*}$ sells its output $Y_{f^{*}, t}^{*}$ in the domestic market under monopolistic competition, setting the price in local currency units. Again, it is assumed that firm $f^{*}$ sets prices in a staggered manner à la Calvo (1983). Each intermediate firm optimally resets prices in a given period $t$ with probability $\left(1-\theta^{*}\right)$. Each firm that does not optimize sets prices according to the indexation scheme:

$$
P_{I M, f^{*}, t}=\left(\pi_{I M, t-1}\right)^{\chi^{*}}\left(\bar{\pi}_{C, t}\right)^{1-\chi^{*}} P_{I M, f^{*}, t-1}
$$

where $P_{I M, f^{*}, t}=P_{X, f^{*}, t}^{*}$ and $\pi_{I M, t}=P_{I M, t-1} / P_{I M, t-2}$, with $P_{I M, t}=P_{X, t}^{*}$. The last equality follows from the assumption that the foreign exporting firm sets the price in domestic currency units.

As before, each foreign firm that re-optimizes its price in period $t$ maximizes the discounted sum of future expected nominal profits:

$$
E_{t}=\left[\sum_{k=0}^{\infty}\left(\theta^{*}\right)^{k} \lambda_{t, t+k}^{*} D_{f^{*}, t+k}^{*} / S_{t+k}\right]
$$


subject to the price indexation scheme (Equation (44)) and the domestic demand for its output, $I M_{f^{*}, t}=$ $X_{f^{*}, t}^{*}$ (derived below), where

$$
D_{f^{*}, t}^{*}=P_{I M, f^{*}, t} I M_{f^{*}, t}-M C_{t}^{*} I M_{f^{*}, t}
$$

with $M C_{t}^{*}=S_{t} P_{Y, t}^{*}$ representing the foreign intermediate-good firm's marginal cost.

The maximization results in the following first-order condition characterizing the foreign intermediategood producer's optimal pricing decision for its output sold in the domestic market:

$$
E_{t}\left[\sum_{k=0}^{\infty}\left(\theta^{*}\right)^{k} \lambda_{t, t+k}^{*}\left(\Pi_{I M, t, t+k}^{\dagger} \tilde{P}_{I M, t}-\phi_{t+k}^{*} M C_{t+k}^{*}\right) I M_{f^{*}, t+k} / S_{t+k}\right]=0
$$

The associated aggregate index evolves according to

$$
P_{I M, t}=\left(\left(1-\theta^{*}\right)\left(\tilde{P}_{I M, t}\right)^{\frac{1}{1-\phi_{t}^{*}}}+\theta^{*}\left(\left(\pi_{I M, t-1}\right)^{\chi^{*}}\left(\bar{\pi}_{C, t}\right)^{1-\chi^{*}} P_{I M, t-1}\right)^{\frac{1}{1-\phi_{t}^{*}}}\right)^{1-\phi_{t}^{*}}
$$

while the log-linear import price Phillips curve is then given by:

$$
\begin{aligned}
\left(\hat{\pi}_{I M, t}-\hat{\bar{\pi}}_{C, t}\right)= & \frac{\beta^{*}}{1+\beta^{*} \chi^{*}} E_{t}\left[\hat{\pi}_{I M, t+1}-\hat{\bar{\pi}}_{C, t+1}\right]+\frac{\chi^{*}}{1+\beta^{*} \chi^{*}}\left(\hat{\pi}_{I M, t-1}-\hat{\bar{\pi}}_{C, t}\right) \\
& +\frac{\beta^{*} \chi^{*}}{1+\beta^{*} \chi^{*}} E_{t}\left[\hat{\pi}_{C, t+1}-\hat{\bar{\pi}}_{C, t}\right]+\frac{\left(1-\beta^{*} \theta^{*}\right)\left(1-\theta^{*}\right)}{\theta^{*}\left(1+\beta^{*} \chi^{*}\right)}\left(\widehat{m c}_{t}^{*}+\hat{\phi}_{t}^{*}\right)
\end{aligned}
$$

Again, $\widehat{m c}_{t}^{*}=\hat{s}_{t}+\hat{p}_{Y, t}-\hat{p}_{I M, t}$ represents the average real marginal cost of the foreign intermediate-good firm, with $p_{I M, t}=P_{I M, t} / P_{C, t}$.

\section{Domestic final-good firms}

Following Christoffel et al. (2008), there are four types of final-good firms, combining domestically produced and imported intermediate goods into four distinct non-tradeable final goods: a private consumption good, $Q_{t}^{C}$; a public consumption good, $Q_{t}^{G}$; a private investment good, $Q_{t}^{I}$; and a public investment good, $Q_{t}^{I_{G}}$.

The representative final-good firm producing the private consumption good $Q_{t}^{C}$ combines domestically produced intermediate consumption goods, $H_{t}^{C}$, and imported foreign intermediate consumption goods, $I M_{t}^{C}$, using a constant-returns-to-scale CES technology:

$$
Q_{t}^{C}=\left(v_{C}^{\frac{1}{\mu_{C}}}\left(H_{t}^{C}\right)^{1-\frac{1}{\mu_{C}}}+\left(1-v_{C}\right)^{\frac{1}{\mu_{C}}}\left(I M_{t}^{C}\right)^{1-\frac{1}{\mu_{C}}}\right)^{\frac{\mu_{C}}{\mu_{C}-1}}
$$

where $\mu_{C}$ represents the intertemporal elasticity of substitution between domestic and imported intermediate consumption goods, while the parameter $v_{C}$ measures the share of domestically produced goods in the production of the final consumption good (i.e. home bias).

Defining $H_{f, t}^{C}$ and $I M_{f^{*}, t}^{C}$ as the differentiated output supplied by domestic intermediate-good firm $f$ and the output supplied by foreign exporter $f^{*}$, it follows that:

$$
\begin{gathered}
H_{t}^{C}=\left(\int_{0}^{1}\left(H_{f, t}^{C}\right)^{\frac{1}{\phi_{t}^{H}}} d f\right)^{\phi_{t}^{H}} \\
I M_{t}^{C}=\left(\int_{0}^{1}\left(I M_{f^{*}, t}^{C}\right)^{\frac{1}{\phi_{t}^{*}}} d f^{*}\right)^{\phi_{t}^{*}}
\end{gathered}
$$

where $\phi_{t}^{H}, \phi_{t}^{*}>0$ is defined analogously to $\phi_{t}^{W}$ above and can be interpreted as price markups in the markets for domestic and imported intermediate goods. 
The final-good firm takes prices $P_{H, f, t}$ and $P_{I M, f^{*}, t}$ as given and determines the optimal bundle of intermediate goods by minimizing expenditure on the differentiated goods subject to the aggregation constraints (Equations (51) and (52)). This minimization yields the following set of demand equations for differentiated domestic and foreign intermediate goods:

$$
\begin{gathered}
H_{f, t}^{C}=\left(\frac{P_{H, f, t}}{P_{H, t}}\right)^{-\frac{\phi_{t}^{H}}{\phi_{t}^{H}-1}} H_{t}^{C} \\
I M_{f^{*}, t}^{C}=\left(\frac{P_{I M, f^{*}, t}}{P_{I M, t}}\right)^{-\frac{\phi_{t}^{*}}{\phi_{t}^{*}-1}} I M_{t}^{C}
\end{gathered}
$$

where

$$
\begin{aligned}
P_{H, t} & =\left(\int_{0}^{1}\left(P_{H, f, t}\right)^{\frac{1}{1-\phi_{t}^{H}}} d f\right)^{1-\phi_{t}^{H}} \\
P_{I M, t} & =\left(\int_{0}^{1}\left(P_{I M, f^{*}, t}\right)^{\frac{1}{1-\phi_{t}^{*}}} d f^{*}\right)^{1-\phi_{t}^{*}}
\end{aligned}
$$

are the aggregate price indices for the bundles of domestic and foreign intermediate goods, respectively.

Taking the price indices as given, the consumption-good firm chooses the bundles $H_{t}^{C}$ and $I M_{t}^{C}$ that minimize $P_{H, t} H_{t}^{C}+P_{I M, t} I M_{t}^{C}$ subject to the aggregation constraint (Equation (50)), yielding the demand equations for the domestic and intermediate-good bundles:

$$
\begin{gathered}
H_{t}^{C}=v_{C}\left(\frac{P_{H, t}}{P_{C, t}}\right)^{-\mu_{C}} Q_{t}^{C} \\
I M_{t}^{C}=\left(1-v_{C}\right)\left(\frac{P_{I M, t}}{P_{C, t}}\right)^{-\mu_{C}} Q_{t}^{C}
\end{gathered}
$$

where

$$
P_{C, t}=\left(v_{C}\left(P_{H, t}\right)^{1-\mu_{C}}+\left(1-v_{C}\right)\left(P_{I M, t}\right)^{1-\mu_{C}}\right)^{\frac{1}{1-\mu_{C}}}
$$

is the price of a unit of the consumption good.

The representative firm producing the non-tradeable final private investment good is modelled in an analogous manner. Specifically, the firm combines domestically produced intermediate investment goods with imported foreign intermediate investment goods using the following constant-returns-to-scale CES technology:

$$
Q_{t}^{I}=\left(v_{I}^{\frac{1}{\mu_{I}}}\left(H_{t}^{I}\right)^{1-\frac{1}{\mu_{I}}}+\left(1-v_{I}\right)^{\frac{1}{\mu_{I}}}\left(I M_{t}^{I}\right)^{1-\frac{1}{\mu_{I}}}\right)^{\frac{\mu_{I}}{\mu_{I}-1}}
$$

where all other variables related to the production of the intermediate good-the optimal demand for inputs, $H_{f, t}^{I}, H_{t}^{I}, I M_{f^{*}, t}^{I}, I M_{t}^{I}$, as well as the price of a unit of the investment good, $P_{I, t}$-are defined or derived analogously to that for the consumption good.

In contrast, full home bias is assumed in the production of the non-tradeable final public consumption good, $Q_{t}^{G}$. That is, it is assumed to be a composite made only of domestic intermediate goods-that is, $Q_{t}^{G}=H_{t}^{G}$ with

$$
H_{t}^{G}=\left(\int_{0}^{1}\left(H_{f, t}^{G}\right)^{\frac{1}{\phi_{t}^{H}}} d f\right)^{\phi_{t}^{H}}
$$

The optimal demand for the intermediate good supplied by firm $f$ is given by

$$
H_{f, t}^{G}=\left(\frac{P_{H, f, t}}{P_{H, t}}\right)^{-\frac{\phi_{H}^{H}}{\phi_{t}^{H}-1}} H_{t}^{G}
$$


and the price of a unit of the public consumption good is $P_{G, t}=P_{H, t}$.

Similarly, the public investment good, $Q_{t}^{I_{G}}$, is assumed to be a composite made up only of domestic intermediate goods-that is, $Q_{t}^{I_{G}}=H_{t}^{I_{G}}$, with price $P_{I_{G}, t}=P_{H, t}$.

Aggregating across firms, the following aggregate demand equations for domestic and foreign intermediate goods hold:

$$
\begin{gathered}
H_{f, t}=H_{f, t}^{C}+H_{f, t}^{I}+H_{f, t}^{I_{G}}+H_{f, t}^{G}=\left(\frac{P_{H, f, t}}{P_{H, t}}\right)^{-\frac{\phi_{t}^{H}}{\phi_{t}^{H}-1}} H_{t} \\
I M_{f^{*}, t}=I M_{f^{*}, t}^{C}+I M_{f^{*}, t}^{I}=\left(\frac{P_{I M, f^{*}, t}}{P_{I M, t}}\right)^{-\frac{\phi_{*}^{*}}{\phi_{t}^{*}-1}} I M_{t}
\end{gathered}
$$

where $H_{t}=H_{t}^{C}+H_{t}^{I}+H_{t}^{I_{G}}+H_{t}^{G}$ and $I M_{t}=I M_{t}^{C}+I M_{t}^{I}$.

\section{Foreign retail firm}

A representative foreign retail firm combines differentiated intermediate goods produced domestically by firm $f$ and sold abroad, $X_{f, t}$, using the following CES technology:

$$
X_{t}=\left(\int_{0}^{1}\left(X_{f, t}\right)^{\frac{1}{\phi_{t}^{X}}} d f\right)^{\phi_{t}^{X}}
$$

The foreign retailer takes its input prices $P_{X, f, t} / S_{t}$ as given and chooses the optimal bundle of differentiated inputs by minimizing expenditure on the bundle of differentiated intermediate goods subject to the aggregation constraint (65), yielding the following demand equation:

$$
X_{f, t}=\left(\frac{P_{X, f, t}}{P_{X, t}}\right)^{-\frac{\phi_{X}^{X}}{\phi_{t}^{X}-1}} X_{t}
$$

where

$$
P_{X, t}=\left(\int_{0}^{1}\left(P_{X, f, t}\right)^{\frac{1}{1-\phi_{t}^{X}}} d f\right)^{1-\phi_{t}^{X}}
$$

is the aggregate price index for the bundle of exported domestic intermediate goods (priced in producer currency).

The retailer takes this price index as given and supplies the quantity of the export bundle, $X_{t}$, that satisfies foreign demand. The latter is given by an equation similar in structure to the domestic import equation:

$$
X_{t}=v^{*}\left(\frac{P_{X, t} / S_{t}}{P_{Y, t}^{*}}\right)^{-\mu_{*}} Y_{t}^{*}
$$

where $\mu^{*}$ is the price elasticity of exports and $v^{*}$ is the export share of the domestic intermediate-good firms. This latter parameter captures specific non-price related foreign preferences for domestic goods. $Y_{t}^{*}$ is a measure of overall foreign demand.

\subsection{Monetary authority}

The monetary authority sets the short-term interest rate according to a simple log-linear interest rate rule:

$$
\hat{r}_{t}=\phi_{R} \hat{r}_{t-1}+\left(1-\phi_{R}\right)\left(\hat{\bar{\pi}}_{C, t}+\phi_{\pi}\left(\hat{\pi}_{C, t-1}-\hat{\bar{\pi}}_{C, t}\right)+\phi_{Y} \hat{y}_{t}\right)+\phi_{\Delta \pi}\left(\hat{\pi}_{C, t}-\hat{\pi}_{C, t-1}\right)+\phi_{\Delta Y}\left(\hat{y}_{t}-\hat{y}_{t-1}\right)+\hat{\eta}_{t}^{R}
$$


where $\hat{r}_{t}=\log \left(R_{t} / R\right)$ is the log-deviation of the (gross) nominal interest rate from its steady-state value. Similarly, $\hat{\pi}_{C, t}=\log \left(\pi_{C, t} / \bar{\pi}_{C}\right)$ denotes the $\log$-deviation of quarter-on-quarter consumer price inflation, $\pi_{C, t}=P_{C, t} / P_{C, t-1}$ from the monetary authority's long-run inflation objective, $\bar{\pi}_{C}$, while $\hat{\bar{\pi}}_{C, t}=$ $\log \left(\bar{\pi}_{C, t} / \bar{\pi}_{C}\right)$ represents the log-deviation of the monetary authority's possible inflation target from its equilibrium value. The latter is assumed to follow a serially uncorrelated process with mean zero:

$$
\hat{\bar{\pi}}_{C, t}=\rho_{\bar{\pi}} \hat{\bar{\pi}}_{C, t-1}+\hat{\eta}_{t}^{\bar{\pi}}
$$

Additionally, the monetary authority takes into account the current state of the economy, where $\hat{y}_{t}=\widehat{Y_{t} / z_{t}}$ denotes the log-deviation of aggregate output from trend output - that is, the output gap. Finally, $\eta_{t}^{R}$ represents a serially uncorrelated shock to the nominal interest rate. Note that, as in Du Plessis et al. (2014) and based on the findings of Alpanda et al. (2010) for South Africa, it is assumed that the central bank's policy rule does not respond to fluctuations in the real exchange rate.

\subsection{Fiscal authority}

The fiscal authority purchases the public consumption good, $G_{t}$, invests in public capital, $I_{G, t}$, issues bonds to refinance its debt, $B_{t}$, makes transfer payments, $T R_{t}$, and levies different types of taxes. The fiscal authority's period-by-period budget constraint has the following form:

$$
\begin{aligned}
& P_{G, t} G_{t}+P_{I_{G}, t} I_{G, t}+B_{t}+T R_{t}= \\
& \tau_{t}^{c} P_{C, t} C_{t}+\tau_{t}^{w} W_{t} N_{t}+\tau_{t}^{k}\left(R_{K, t} u_{t}-\left(\Gamma_{u}\left(u_{t}\right)+\delta\right) P_{I, t}\right) K_{t}+\frac{B_{t+1}}{R_{t}}
\end{aligned}
$$

where $P_{G, t}$ and $P_{I_{G}, t}$ are the prices of the public consumption good and the public investment good respectively, which, under the assumption of full home bias, is just equal to the domestic price level, $P_{H, t}{ }^{7}$

Following Leeper et al. (2010), Coenen et al. (2012), Born et al. (2013), and Leeper et al. (2017), among others, the fiscal instruments are assumed to follow the prescriptions of simple feedback rules. These rules embed two features. First, the rules incorporate automatic stabilizers through the inclusion of a contemporaneous response of the relevant fiscal variable to the output gap. Second, all fiscal instruments are permitted to respond to deviations of government debt from its steady-state level in an effort to stabilize public debt. ${ }^{8}$

Spending rules are given by:

$$
\begin{aligned}
\hat{g}_{t} & =\phi_{G} \hat{g}_{t-1}-\theta_{G, Y} \hat{y}_{t}-\theta_{G, B} \hat{b}_{t}+\hat{\varepsilon}_{t}^{G} \\
\hat{i}_{G, t} & =\phi_{I_{G}} \hat{i}_{G, t-1}-\theta_{I_{G}, Y \hat{y}_{t}}-\theta_{I_{G}, B} \hat{b}_{t}+\hat{\varepsilon}_{t}^{I_{G}} \\
t \hat{r}_{t} & =\phi_{T R} \hat{r}_{t-1}-\theta_{T R, Y} \hat{y}_{t}-\theta_{T R, B} \hat{b}_{t}+\hat{\varepsilon}_{t}^{T R}
\end{aligned}
$$

Tax rules are given by:

$$
\begin{aligned}
& \check{\tau}_{t}^{w}=\phi_{W} \check{\tau}_{t-1}^{w}+\theta_{W, Y} \hat{y}_{t}+\theta_{W, B} \hat{b}_{t}+\hat{\varepsilon}_{t}^{\tau^{w}} \\
& \check{\tau}_{t}^{k}=\phi_{K} \check{\tau}_{t-1}^{k}+\theta_{K, Y} \hat{y}_{t}+\theta_{K, B} \hat{b}_{t}+\hat{\varepsilon}_{t}^{\tau^{k}} \\
& \check{\tau}_{t}^{c}=\phi_{C} \check{\tau}_{t-1}^{c}+\theta_{C, Y} \hat{y}_{t}+\theta_{C, B} \hat{b}_{t}+\hat{\varepsilon}_{t}^{\tau^{c}}
\end{aligned}
$$

where the " $"$ ' symbol denotes percentage-point deviations from the steady-state tax rate as in Coenen et al. (2013) and the $\varepsilon$ are exogenous AR(1) processes. This type of specification for the so-called fiscal

\footnotetext{
${ }^{7}$ Note that the aggregate quantity of a household-specific variable, $X_{h, t}$, is given by $X_{t}=\int_{0}^{1} X_{h, t} d h=(1-\omega) X_{i, t}+\omega X_{j, t}$.

${ }^{8}$ The assumptions will be relaxed and simulations run using different specifications of the fiscal rules.
} 
reaction function has its origin in the work of Henning Bohn (see Bohn (1998), in which the author showed that the sustainability of fiscal policy can be assessed by estimating a fiscal reaction function of the type presented above). ${ }^{9}$. There is also a rich history of investigating fiscal reaction functions in South Africa outside the context of DSGE models (see, for example, Burger and Marinkov 2012; Burger et al. 2015, 2012).

The fiscal rules in Equations (72)-(77) are consistent with the idea that debt stabilization is an important consideration in the formulation of fiscal policy. Additionally, as shown by Ravn et al. (2007), such linear tax rules can in fact approximate optimal rules.

The inclusion of an automatic stabilizer component in the transfer rule is particularly important. Given the assumption that the output gap enters the transfer rule with a negative coefficient, any expansionary fiscal shock that brings about an increase in aggregate activity (and, therefore, an expansion in employment) by construction induces a reduction in transfers to households. The decline in transfers will in turn offset the possible increase in disposable income of non-Ricardian households stemming from the increase in economic activity and the concomitant increase in labour income. This might dampen the overall impact of the expansionary fiscal shock.

By adjusting these fiscal feedback rules, both on the revenue and expenditure side, the macroeconomic impact of using different instruments to stabilize debt in the face of a shock can be investigated. This can be done by 'switching' the feedback variables in the expenditure and tax equations on and off. By removing these feedback terms from one or more of the equations, the instrument that will respond to a shock in order to stabilize debt can be specified.

Note also that in order to guarantee longer-term debt sustainability, the debt feedback coefficient $\left(\theta_{*, B}\right)$ must be non-zero for at least one instrument. Findings in the literature show that it generally suffices to assume a small and inertial response of the chosen instrument(s) to deviations in debt. ${ }^{10}$

\subsection{Aggregation and market clearing}

Given that households within each of the two groups (Ricardian and non-Ricardian) are identical, the aggregate quantity of a household-specific variable, $X_{h, t}$, is given by $X_{t}=\int_{0}^{1} X_{h, t} d h=(1-\omega) X_{i, t}+\omega X_{j, t}$. For example, aggregate consumption is given by $C_{t}=(1-\omega) C_{i, t}+\omega C_{j, t}$. Any variable that only relates to Ricardians is given by $X_{t}=(1-\omega) X_{i, t}$; for example, the aggregate private capital stock is given by $K_{t}=(1-\omega) K_{i, t}$.

Market clearing in labour markets. Each household $h$ supplies its labour in a monopolistically competitive market. In equilibrium, the total supply of the individual households' differentiated labour service must equal the intermediate-good firm's demand for labour:

$$
N_{h, t}=\int_{0}^{1} N_{f, t}^{h} d f=N_{t}^{h}
$$

Aggregating over all households $h$ we have

$$
\begin{aligned}
\int_{0}^{1} N_{h, t} d h & =\int_{0}^{1} N_{t}^{h} d h \\
& =\int_{0}^{1}\left(\frac{W_{h, t}}{W_{t}}\right)^{-\frac{\phi_{t}^{W}}{\phi_{t}^{H}-1}} N_{t} d h
\end{aligned}
$$

\footnotetext{
${ }^{9}$ See also Bohn $(1995,2007,2011)$

${ }^{10}$ The literature on optimal fiscal policy derives two stylized results. First, small, permanent shifts in fiscal instruments are preferred to large, sudden moves. Second, mild countercyclical policies can have stabilizing and welfare-enhancing effects (Stähler and Thomas 2012)
} 
The aggregate wage sum paid by firms is given by

$$
\int_{0}^{1} W_{h, t} N_{h, t} d h=N_{t} \int_{0}^{1} W_{h, t}\left(\frac{W_{h, t}}{W_{t}}\right)^{-\frac{\phi_{t}^{W}}{\phi_{t}^{W}-1}} d h=W_{t} N_{t}
$$

where the first equality is obtained by using the aggregate demand for labour services of variety $h$ (combining Equations (32) and (78)), while the second equality uses the properties of the aggregate wage index $W_{t}$.

Market clearing in the capital market. Market clearing in the rental market for capital services implies that the effective capital utilization rate satisfies the following condition:

$$
u_{t} K_{t}=u_{t} \int_{0}^{1} K_{h, t} d h=\int_{0}^{1} K_{f, t}^{s} d f=K_{t}^{s}
$$

Market clearing in the market for domestic intermediate goods. Each intermediate-good producing firm $f$ acts as a price setter in domestic and foreign markets. Therefore, in equilibrium the supply of its differentiated output needs to equal domestic and foreign demand:

$$
Y_{f, t}=H_{f, t}+X_{f, t}
$$

Aggregating over the continuum of firms gives the following aggregate resource constraint:

$$
\begin{aligned}
Y_{t}=\int_{0}^{1} Y_{f, t} d f & =\int_{0}^{1} H_{f, t} d f+\int_{0}^{1} X_{f, t} d f \\
& =\int_{0}^{1}\left(\frac{P_{H, f, t}}{P_{H, t}}\right)^{-\frac{\phi_{t}^{H}}{\phi_{t}^{H}}} H_{t} d f+\int_{0}^{1}\left(\frac{P_{X, f, t}}{P_{X, t}}\right)^{-\frac{\phi_{t}^{X}}{\phi_{X}^{X}}} X_{t} d f
\end{aligned}
$$

Expressing Equation (83) in nominal terms gives the following nominal resource constraint:

$$
\begin{aligned}
P_{Y, t} Y_{t} & =\int_{0}^{1} P_{H, f, t} H_{f, t} d f+\int_{0}^{1} P_{X, f, t} X_{f, t} d f \\
& =H_{t} \int_{0}^{1} P_{H, f, t}\left(\frac{P_{H, f, t}}{P_{H, t}}\right)^{-\frac{\phi_{t}^{H}}{\phi_{t}^{H}-1}} d f+X_{t} \int_{0}^{1} P_{X, f, t}\left(\frac{P_{X, f, t}}{P_{X, t}}\right)^{-\frac{\phi_{X}^{X}}{\phi_{t}^{X}-1}} d f \\
& =P_{H, t} H_{t}+P_{X, t} X_{t}
\end{aligned}
$$

where the second-to-last equality follows from the aggregate demand relationships for the domestic intermediate goods sold in home and foreign markets, $H_{f, t}$ and $X_{f, t}$, while the last equality uses the properties of the aggregate price indices, $P_{H, t}$ and $P_{X, t}$.

Market clearing in market for imported intermediate goods. Each foreign exporter, $f^{*}$, acts as a price setter in the domestic market. Hence, in equilibrium, the supply of its differentiated good must equal demand, $I M_{f^{*}, t}$.

Aggregating over the continuum of foreign firms $f^{*}$, we have

$$
\int_{0}^{1} I M_{f^{*}, t} d f^{*}=\int_{0}^{1}\left(\frac{P_{I M, f^{*}, t}}{P_{I M, t}}\right)^{-\frac{\phi_{*}^{*}}{\phi_{t}^{*}-1}} I M_{t} d f^{*}
$$

Market clearing in the final-goods market. Market clearing in the fully competitive, final-good market implies:

$$
\begin{aligned}
Q_{t}^{C} & =C_{t} \\
Q_{t}^{I} & =I_{t}+\Gamma_{u}\left(u_{t}\right) K_{t} \\
Q_{t}^{I_{G}} & =I_{G, t} \\
Q_{t}^{G} & =G_{t}
\end{aligned}
$$


Combining the market-clearing conditions for domestic intermediate-good and final-good markets results in an expression for the nominal aggregate resource constraint:

$$
\begin{aligned}
P_{Y, t} Y_{t} & =P_{H, t} H_{t}+P_{X, t} X_{t} \\
& =P_{C, t} C_{t}+P_{I, t}\left(I_{t}+\Gamma_{u}\left(u_{t}\right) K_{t}\right)+P_{I_{G}, t} I_{G, t}+P_{G, t} G_{t}+P_{X, t} X_{t} \\
& -P_{I M, t}\left(I M_{t}^{C}+I M_{t}^{I}\right)
\end{aligned}
$$

where the last equality uses the demand functions for the bundles of the domestic and foreign intermediate goods used in the production of the final consumption and investment goods, $H_{t}^{C}$ and $H_{t}^{I}$, as well as $I M_{t}^{C}$ and $I M_{t}^{I}$, along with the prices of the two types of final goods, $P_{C, t}$ and $P_{I, t}$. Finally, under the assumption of full home bias in government consumption and investment, $P_{G, t}=P_{I_{G}, t}=P_{H, t}$.

Market clearing in the domestic bond market. The equilibrium holdings of domestic bonds evolve over time according to the fiscal authority's budget constraint, reflecting the fiscal authority's need to issue debt in order to finance its deficit. That is, new bond issuance is equal to the difference between government expenditure and revenue:

$$
\left[\frac{B_{t+1}}{R_{t}}-B_{t}\right]=G E_{t}-G R_{t}
$$

with $G E_{t} \equiv$ total government expenditure and $G R_{t} \equiv$ total government revenue. At any given point in time, the supply of domestic bonds is fully elastic and matches the (net) holdings of domestic bonds accumulated by households:

$$
B_{t}=\int_{0}^{1} B_{h, t} d h
$$

Market clearing in the foreign bond market. At any given point in time, the supply of internationally traded foreign bonds is fully elastic and matches the (net) holdings of foreign bonds accumulated by domestic households:

$$
B_{t}^{*}=\int_{0}^{1} B_{h, t}^{*} d h
$$

\subsection{Net foreign assets and the trade balance}

The domestic economy's net foreign assets equal the economy-wide net holdings of foreign bonds (denominated in foreign currency) and evolve according to

$$
\frac{B_{t+1}^{*}}{R_{t}^{*}}=B_{t}^{*}+\frac{T B_{t}}{S_{t}}
$$

where

$$
T B_{t}=P_{X, t} X_{t}-P_{I M, t} I M_{t}
$$

is the domestic economy's trade balance. ${ }^{11}$ For convenience, net foreign assets, as well as the trade balance, can be expressed as a share of domestic output. That is, $s_{B^{*}, t+1}=S_{t} B_{t+1}^{*} / P_{Y, t} Y_{t}$ and $s_{T B, t}=$ $T B_{t} / P_{Y, t} Y_{t}$.

\subsection{Foreign economy}

Following Steinbach (2014) and Du Plessis et al. (2014), the foreign economy is modelled as a standard three-equation closed-economy DSGE model:

$$
\hat{y}_{t}^{*}=E_{t} \hat{y}_{t+1}^{*}-\frac{1}{\sigma^{*}}\left(\hat{r}_{t}^{*}-E_{t} \hat{\pi}_{t+1}^{*}+\hat{\varepsilon}_{t}^{y^{*}}\right)
$$

\footnotetext{
${ }^{11}$ Importantly, the existence of a financial intermediation premium ensures that domestic holdings of foreign bonds are zero in the non-stochastic steady state.
} 


$$
\begin{gathered}
\hat{\pi}_{t}^{*}=\beta^{*} E_{t} \hat{\pi}_{t+1}^{*}+\kappa^{*} \hat{y}_{t}^{*}+\hat{\varepsilon}_{t}^{\pi^{*}} \\
\hat{r}_{t}^{*}=\phi_{R}^{*} \hat{r}_{t-1}^{*}+\left(1-\phi_{R}^{*}\right)\left[\phi_{\pi}^{*} \hat{\pi}_{t}^{*}+\phi_{y}^{*} \hat{y}_{t}^{*}\right]+\eta_{t}^{R^{*}}
\end{gathered}
$$

where $\hat{y}_{t}^{*}, \hat{\pi}_{t}^{*}$, and $\hat{r}_{t}^{*}$ represent foreign output, inflation, and the policy rate. $\hat{\varepsilon}_{t}^{\psi^{*}}$ and $\hat{\varepsilon}_{t}^{\pi^{*}}$ are $\operatorname{AR}(1)$ shock processes.

\section{$4 \quad$ Estimation}

\subsection{Estimation methodology}

In order to cast the model in state-space form, the model equations are log-linearized. ${ }^{12}$ The state-space representation of the model is given by:

$$
\begin{gathered}
S_{t}=F S_{t-1}+Q \varepsilon_{t} \\
Y_{t}=M+H S_{t-1}+\eta_{t}
\end{gathered}
$$

with

$$
\left[\begin{array}{l}
\varepsilon_{t} \\
\eta_{t}
\end{array}\right] \sim N\left(0,\left[\begin{array}{ll}
\sigma & 0 \\
o & R
\end{array}\right]\right)
$$

where the state vector $S_{t}$ contains the model's endogenous variables, while $Y_{t}$ is the vector of observed variables. The data series used are discussed below. The matrices $F$ and $Q$ are functions of the model parameters, $M$ contains the equilibrium information relating to the observable variables, and $H$ is a mapping function that maps the model variables to the data. $\varepsilon_{t}$ is a vector of innovations to the structural shocks, while $\eta_{t}$ is the vector of measurement errors (Steinbach 2014). The model is estimated using Bayesian techniques, following the approach described by An and Schorfheide (2007), and is implemented in Dynare, a MATLAB pre-processor that allows for the Bayesian estimation of DSGE models. ${ }^{13}$

According to An and Schorfheide (2007), Bayesian estimation offers several advantages when it comes to estimating DSGE models. A major advantage is that Bayesian estimation is by its nature system-based and is, therefore, appropriate for taking large-scale DSGE models to the data. This contrasts to generalized method of moments (GMM) estimators which estimate individual (i.e. equation-by-equation) equilibrium relationships. A further advantage of Bayesian estimation is that it allows the researcher to incorporate additional information with respect to the model parameters by specifying appropriate prior distributions over said parameters. This formalizes the use of prior and/or external information that was prevalent in earlier studies in estimating the parameters of a possibly large and complex DSGE model. As such, Bayesian estimation occupies the middle ground between full maximum likelihood estimation and pure calibration (Steinbach 2014).

\subsection{Data}

A total of 22 observable time series are used, comprising both domestic and foreign macroeconomic variables. The sample period runs from 1994Q1 to 2018Q4. Data for the South African economy was

\footnotetext{
12 The full set of log-linear equations are available from the authors on request.

${ }^{13}$ In this application, the estimation procedure uses the Metropolis-Hastings (MH) Markov chain Monte Carlo (MCMC) algorithm with 300,000 draws for two chains (with a burn-in of 0.15 ). To ensure that the tails of the posterior mode are identified, the scale used for the jumping distribution is adjusted to ensure an acceptance rate of approximately 2 per cent.
} 
largely sourced from the South African Reserve Bank (SARB) Quarterly Bulletin. ${ }^{14}$ The exceptions are consumer price index (CPI) and producer price index (PPI) data that were sourced from Statistics South Africa. Following Steinbach (2014), data for South Africa's trading partners was sourced from the Global Projection Model of the Center for Economic Research and its Applications (CEPREMAP). Foreign variables were constructed as the trade-weighted sum of the country-specific quantities. Table 1 lists the time series used as well as their respective sources. Note that the nominal effective exchange rate is the indirect measure published by the SARB, implying that an increase denotes an appreciation. This index was inverted before being used in estimation to conform to the model definition of the exchange rate-that is, a decrease signifies an appreciation.

Given the fact that the log-linearized model presents a stylized representation of the economy, 15 of the 22 observable variables are included with measurement error to account for possible mismatch between the theoretical model variables and their real-world counterparts. To that end, $\mathrm{R}$ in Equation (101) is calibrated so that measurement error accounts for approximately 15 per cent of the variation in the observed data.

Table 1: Observable variables

\begin{tabular}{lll}
\hline Variable & Description & Source \\
\hline Domestic economy & Real GDP & \\
$\Delta \ln \left(\tilde{Y}_{t}\right)$ & Private consumption & \\
$\Delta \ln \left(\tilde{C}_{t}\right)$ & Government consumption & \\
$\Delta \ln \left(\tilde{G}_{t}\right)$ & Private sector fixed investment & \\
$\Delta \ln \left(\tilde{I}_{t}\right)$ & Public sector investment & \\
$\Delta \ln \left(\tilde{I}_{G, t}\right)$ & Total exports & South African Reserve Bank \\
$\Delta \ln \left(\tilde{X}_{t}\right)$ & Total imports & \\
$\Delta \ln \left(\tilde{M}_{t}\right)$ & Nominal effective exchange rate & \\
$\Delta \ln \left(\tilde{S}_{t}\right)$ & Non-agricultural employment & \\
$\Delta \ln \left(\tilde{E}_{t}\right)$ & Real remuneration per worker in the non-agricultural sector & \\
$\Delta \ln \left(\tilde{W}_{t}\right)$ & Government transfers to households & \\
$\Delta \ln \left(\tilde{T} R_{t}\right)$ & Repo rate & \\
$\tilde{R}_{t}$ & Investment deflator & \\
$\tilde{\pi}_{I, t}$ & & \\
$\tilde{\pi}_{H, t}$ & PPI inflation & Statistics South Africa \\
$\tilde{\pi}_{C, t}$ & CPI inflation & \\
$\tilde{\pi}_{C, t}$ & Inflation target & Author's calculations \\
$\Delta \tilde{\tau}_{t}^{w}$ & Labour tax rate & \\
$\Delta \tilde{\tau}_{t}^{k}$ & Capital tax rate & \\
$\Delta \tilde{\tau}_{t}^{c}$ & Consumption tax rate & \\
Foreign economy & & \\
$\Delta \ln \left(\tilde{Y}_{t}^{*}\right)$ & Real GDP (trade weighted) & \\
$\tilde{R}_{t}^{*}$ & Colicy interest rates (trade weighted) & \\
$\tilde{\pi}_{t}^{*}$ & CPI inflation (trade weighted) & \\
\hline
\end{tabular}

Source: authors' compilation.

\section{Calculation of tax rates}

Effective tax rates are calculated as follows.

\footnotetext{
${ }^{14}$ Public expenditure and investment data used in the estimation of the fiscal reaction functions are sourced from the System of National Accounts, while revenue data are sourced from the National Revenue Accounts. Both sets of data are documented in the Quarterly Bulletin.
} 
Labour tax rate $\left(\tau^{w}\right)$. The labour tax rate is calculated as the ratio between personal income taxes and total nominal compensation of employees:

$$
\tau_{t}^{w}=\frac{T P_{t}}{C O M P_{t}}
$$

where $T P_{t}$ is total personal income taxes and $C O M P_{t}$ is total compensation. Both constituent series are sourced from the SARB Quarterly Bulletin.

Capital tax rate $\left(\tau^{k}\right)$. The capital tax rate is calculated as the ratio between the sum of total corporate taxes and taxes on property and net operating surplus:

$$
\tau_{t}^{k}=\frac{T C_{t}+T P R O P_{t}}{N O S_{t}}
$$

where $T C_{t}$ is total corporate taxes, $T P R O P_{t}$ is taxes on property, and $N O S_{t}$ is net operating surplus. Constituent series are sourced from the SARB Quarterly Bulletin.

Consumption tax rate $\left(\tau^{c}\right)$. The consumption tax rate is calculated as the ratio between total taxes on goods and services and the difference between private consumption and taxes on goods and services:

$$
\tau_{t}^{c}=\frac{T G O O D_{t}}{C P_{t}-T G O O D_{t}}
$$

where $T G O O D_{t}$ is taxes on goods and services and $C P_{t}$ is (nominal) private consumption spending. Constituent series are sourced from the SARB Quarterly Bulletin.

As mentioned by Born et al. (2013), using average effective tax rates may be problematic for several reasons. First, there is no clear division between labour and capital taxes, which are theoretical constructs. Second, using average effective tax rates is problematic in the presence of a progressive labour income tax schedule as it is legislated marginal tax rates rather than average effective tax rates that affect behaviour. Nevertheless, for comparability with the existing literature, average effective tax rates are constructed. While this is clearly a simplifying assumption, it can be justified on the grounds that the dynamics of marginal and average tax rates are very similar.

\section{Inflation targeting and the model structure}

The SARB officially adopted inflation targeting in the year 2000. However, it can be argued that the SARB unofficially targeted some measure of inflation throughout the 1990s. That being said, the official measure only entered the target range of 3-6 per cent in 2003Q4 - close to four years after the (official) implementation of inflation targeting. The period before was characterized by excessively high inflation and interest rates. Following Steinbach (2014), it is assumed that the unofficial inflation target during this period most likely exceeded the model's calibrated steady-state inflation rate of 4.5 per cent. To that end, the model's inflation target variable $\tilde{\bar{\pi}}_{C, t}$ enters as an additional observable variable, with the time-varying target calculated by means of a Hodrick-Prescott filter that converges to 4.5 per cent (the midpoint of the official target band) in 2004. Figure 1 plots this estimated inflation target. The inclusion of this time-varying inflation target does not affect the model's steady state or model dynamics, but it does affect estimation of the parameters in the Phillips curves and the Taylor rule.

\subsection{Calibration}

While the model is estimated using Bayesian techniques, a sizeable share of the parameters is nevertheless calibrated. In particular, those parameters that affect the model's non-stochastic steady state, as well as those parameters that are not suitably identified, are calibrated using external information (the authors are able to provide details on the computation of the steady state on request). 


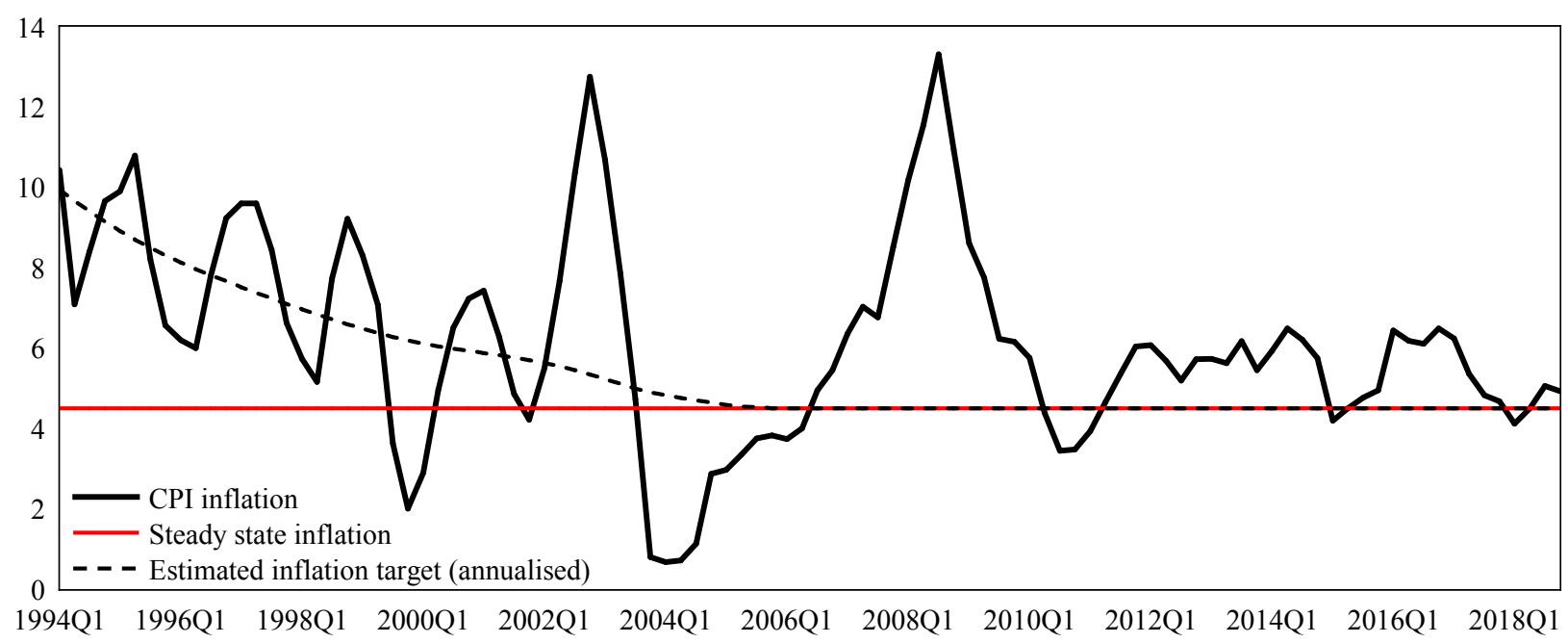

Source: author's calculations, based on data from the SARB.

The model's steady-state growth rate, $g_{z}$, is set equal to 1.0067, which implies a steady-state economywide growth rate of 2.7 per cent-roughly the average growth rate of GDP over the sample. Some of the model's key steady-state ratios are fixed to match their empirical counterparts. These include the expenditure shares of private consumption, private investment, public sector investment, and government consumption, which are set equal to 62.2, 12.6, 5.7, and 19.5 per cent of nominal GDP, respectively. The export and import shares are set to 28.2 per cent, ensuring balanced trade in the steady state.

As mentioned above, the steady-state rate of inflation in the model, $\bar{\pi}$, is set equal to the midpoint of the SARB's official target band, yielding an annual rate of 4.5 per cent. Conditional on the model's steadystate growth rate and steady-state rate of inflation, the discount factor $\beta$ is chosen to deliver an annualized steady-state nominal interest rate of 9.8 per cent—roughly equal to the average policy interest rate over the sample. Since $R=\left(\bar{\pi} g_{z}\right) / \beta$, this implies that $\beta=0.994$.

The share of private consumption in the aggregate consumption bundle, $\alpha_{G}$, is set equal to 0.75 . This parameter value implies roughly equal marginal utilities of private (Ricardian) consumption and government consumption (Coenen et al. 2013). On the supply side, the capital share of production is set equal to 0.3 - that is, $\alpha=0.3$. The share of private capital in the CES aggregate, $\alpha_{K}$, is set equal to 0.9 . This ensures roughly equal marginal products of private and public capital. The depreciation rates for private capital, $\delta$, and public capital, $\delta_{G}$, are set equal to 0.015 and 0.008 , respectively, implying annual deprecation rates of 6 and 3.5 per cent. The parameters that govern the adjustment cost of capital utilization, $\gamma_{u, 1}$ and $\gamma_{u, 2}$, are calibrated as follows: $\gamma_{u, 1}$ is pinned down by the steady-state calculation as $\gamma_{u, 1}=r_{K} / \bar{\pi}$, while $\gamma_{u, 2}$ is set such that the ratio of the two parameters is equal to 0.1 , matching the parameterization in Steinbach (2014).

Turning to the fiscal sector, steady-state tax rates are calibrated to match the average effective tax rates in the data, measured as the revenue-to-tax base ratio. Specifically, the steady-state values for indirect (or consumption) taxes, $\tau^{c}$, labour taxes, $\tau^{w}$, and capital taxes, $\tau^{k}$, are set equal to 16.7, 19.1, and 20.3 per cent, respectively. Regarding government debt, the steady-state debt-to-GDP ratio is fixed at 50 per cent per annum. This is higher than the sample average of approximately 37 per cent. However, South Africa's debt-to-GDP has increased substantially over the last decade, from below 25 per cent in 2008 to close to 60 per cent in 2018. Given the current low-growth environment and the increasing demands on the fiscus, this trend is likely to continue into the foreseeable future. As such, the steady-state debtto-GDP is calibrated at a relatively conservative 50 per cent per annum. 
The inverted Frisch elasticity of labour supply, $\sigma_{L}$ is set equal to 5, following Steinbach (2014). The shares of domestic production in aggregate consumption and investment, $v_{C}$ and $v_{I}$, are calibrated so as to ensure that the steady-state ratios of total imports and exports to GDP match their sample means of roughly 28 per cent. Following Steinbach (2014), $\theta_{W}$ and $\chi_{W}$ are both set equal to 0.75 . The calibration implies that wage contracts are re-optimized once per year, with a relatively high degree of indexation to past inflation. The steady-state wage markup, $\phi_{W}$, follows Adolfson et al. (2007) and Steinbach (2014) and is calibrated at 1.05, while $\phi_{H}$ is calibrated to 1.1. The substitution elasticities for consumption, investment, and foreign goods are calibrated to $1.5,1.5$, and 1.25, respectively. Steady-state foreign inflation is calibrated to match the sample mean of roughly 2 per cent per annum. Table 2 summarizes the calibrated parameters.

Table 2: Calibrated parameters

\begin{tabular}{|c|c|c|c|c|c|}
\hline$\beta$ & Discount factor & 0.994 & $g_{z}$ & Permanent technology growth & 1.0067 \\
\hline $\bar{\pi}$ & Steady-state inflation & 1.011 & $\alpha_{G}$ & Share of private consumption in CES aggregate & 0.75 \\
\hline$\alpha$ & Capital share in production & 0.3 & $\alpha_{K}$ & Share of private capital in CES aggregate & 0.9 \\
\hline$\delta$ & Depreciation rate: private capital & 0.015 & $\delta_{G}$ & Depreciation rate: public capital & 0.008 \\
\hline$B_{Y}$ & Government debt-to-GDP ratio & 0.5 & $\sigma_{L}$ & Labour supply elasticity & 5 \\
\hline$v_{C}$ & Consumption domestic share & 0.64 & $\mathrm{v}_{I}$ & Investment domestic share & 0.52 \\
\hline$\theta_{W}$ & Calvo: wage setting & 0.75 & $\chi_{W}$ & Indexation: wage setting & 0.75 \\
\hline$\phi_{W}$ & Wage setting markup & 1.05 & $\phi_{H}$ & Domestic price markup & 1.1 \\
\hline$\mu_{C}$ & Subst. elasticity: consumption & 1.5 & $\mu_{I}$ & Subst. elasticity: investment & 1.5 \\
\hline$\mu^{*}$ & Subst. elasticity: foreign & 1.25 & $\pi^{*}$ & Foreign inflation & 1.005 \\
\hline$s_{C}$ & Private consumption share & 0.622 & $s_{I}$ & Private investment share & 0.126 \\
\hline$s_{I_{G}}$ & Public investment share & 0.057 & $s_{G}$ & Government consumption share & 0.195 \\
\hline$s_{X}$ & Export share & 0.282 & $s_{I M}$ & Import share & 0.282 \\
\hline
\end{tabular}

Source: authors' compilation.

\subsection{Prior distributions}

The prior means for the set of estimated parameters are summarized in Table 3 and largely follow Christoffel et al. (2008), Leeper et al. (2010), Coenen et al. (2013), and Steinbach (2014).

As the share parameters, $\omega$ and $\bar{\omega}$, are bounded between 0 and 1 , they are assumed to follow a beta distribution. Similarly, the degree of habit persistence is also assumed to follow a beta distribution around 0.65 . The prior for the investment adjustment cost parameter, $\phi_{i}$, follows a normal distribution with a mean of 8 .

Given that the elasticities $v_{G}$ and $v_{K}$ in the CES aggregates for consumption and the capital stock are restricted to be positive, the prior is assumed to follow a gamma distribution with mean 1 (corresponding to the Cobb-Douglas case) and standard deviation 0.2.

Turning to price setting, the Calvo $(\theta)$ and indexation parameters $(\chi)$ are bounded to lie between 0 and 1 and are assumed to follow beta distributions. Importantly, the size of the prior means on the Calvo parameters reflect the stylized fact that inflation is relatively sticky.

Following Smets and Wouters (2003), among others, the priors for the Taylor rule parameters are fairly standard. However, following Steinbach (2014), a larger weight is placed on both output parameters in order to allow for flexible inflation targeting.

Regarding the feedback coefficients in the fiscal rules, $\theta_{., Y}$ and $\theta_{., B}$, gamma distributions with means of around 0.5 and standard deviations of 0.3 are adopted. For the smoothing coefficients embedded in the fiscal rules, $\rho$., beta distributions are adopted. 
Table 3: Parameter priors and posterior estimation results

\begin{tabular}{|c|c|c|c|c|c|}
\hline \multirow{2}{*}{ Parameter description } & \multicolumn{3}{|c|}{ Prior } & \multicolumn{2}{|r|}{ Posterior } \\
\hline & Density $^{a}$ & Mean & Std dev. & Mean & 90 per cent interval \\
\hline \multicolumn{6}{|c|}{ Share of non-Ricardian households } \\
\hline$\omega$ Total share & $B$ & 0.5 & 0.1 & 0.233 & {$[0.218,0.249]$} \\
\hline $\bar{\omega}$ Transfer share & $B$ & 0.75 & 0.1 & 0.460 & {$[0.328,0.592]$} \\
\hline \multicolumn{6}{|l|}{ Adjustment costs } \\
\hline$\gamma_{I}$ Investment & $G$ & 8.0 & 1.5 & 9.493 & {$[7.095,11.802]$} \\
\hline \multicolumn{6}{|l|}{ Preferences } \\
\hline$\kappa$ Habit formation & $B$ & 0.65 & 0.1 & 0.891 & {$[0.858,0.922]$} \\
\hline \multicolumn{6}{|l|}{ Elasticity of substitution } \\
\hline$v_{K}$ Capital & $G$ & 1.0 & 0.2 & 0.921 & {$[0.606,1.231]$} \\
\hline $\mathrm{v}_{G}$ Consumption & $G$ & 1.0 & 0.2 & 1.013 & {$[0.683,1.319]$} \\
\hline \multicolumn{6}{|l|}{ Calvo parameters } \\
\hline$\theta_{H}$ Domestic prices & $B$ & 0.8 & 0.05 & 0.861 & {$[0.787,0.938]$} \\
\hline$\theta_{X}$ Export prices & $B$ & 0.8 & 0.05 & 0.933 & {$[0.907,0.961]$} \\
\hline$\theta^{*}$ Import prices & $B$ & 0.8 & 0.05 & 0.939 & {$[0.905,0.973]$} \\
\hline \multicolumn{6}{|l|}{ Indexation } \\
\hline$\chi_{H}$ Domestic prices & $B$ & 0.75 & 0.1 & 0.447 & {$[0.285,0.608]$} \\
\hline$\chi_{X}$ Export prices & $B$ & 0.75 & 0.1 & 0.234 & {$[0.139,0.324]$} \\
\hline$\chi^{*}$ Import prices & $B$ & 0.75 & 0.1 & 0.360 & {$[0.224,0.498]$} \\
\hline \multicolumn{6}{|l|}{ Taylor rule } \\
\hline$\phi_{R}$ Smoothing & $B$ & 0.8 & 0.05 & 0.919 & {$[0.901 .0 .939]$} \\
\hline$\phi_{\pi}$ Inflation & $N$ & 1.7 & 0.1 & 1.767 & {$[1.530,2.004]$} \\
\hline$\phi_{Y}$ Output gap & $B$ & 0.25 & 0.05 & 0.261 & {$[0.187,0.335]$} \\
\hline$\phi_{\Delta \pi}$ Inflation (change) & $B$ & 0.3 & 0.1 & 0.168 & {$[0.120,0.219]$} \\
\hline$\phi_{\Delta Y}$ Output gap (change) & $B$ & 0.125 & 0.05 & 0.165 & {$[0.111,0.220]$} \\
\hline \multicolumn{6}{|c|}{ Fiscal policy rules: smoothing coefficients } \\
\hline$\phi_{G}$ Gvt. consumption & $B$ & 0.8 & 0.15 & 0.833 & {$[0.708,0.956]$} \\
\hline$\phi_{I_{G}}$ Gvt. investment & $B$ & 0.8 & 0.15 & 0.582 & {$[0.356,0.837]$} \\
\hline$\phi_{T R}$ Transfers & $B$ & 0.8 & 0.15 & 0.187 & {$[0.059,0.313]$} \\
\hline$\phi_{W}$ Labour taxes & $B$ & 0.5 & 0.2 & 0.147 & {$[0.048,0.242]$} \\
\hline$\phi_{K}$ Capital taxes & $B$ & 0.5 & 0.2 & 0.176 & {$[0.058,0.292]$} \\
\hline$\phi_{C}$ Consumption taxes & $B$ & 0.5 & 0.2 & 0.144 & {$[0.046,0.237]$} \\
\hline \multicolumn{6}{|c|}{ Fiscal policy rules: output feedback coefficients } \\
\hline$\theta_{G, Y}$ Gvt. consumption & $G$ & 0.2 & 0.1 & 0.167 & {$[0.050,0.279$} \\
\hline$\theta_{I_{G}, Y}$ Gvt. investment & $G$ & 0.2 & 0.1 & 0.216 & {$[0.049,0.380]$} \\
\hline$\theta_{T R, Y}$ Transfers & $G$ & 0.2 & 0.1 & 0.204 & {$[0.047,0.353]$} \\
\hline$\theta_{W, Y}$ Labour taxes & $G$ & 0.5 & 0.3 & 0.305 & {$[0.147,0.456]$} \\
\hline$\theta_{K, Y}$ Capital taxes & $G$ & 0.5 & 0.3 & 0.507 & {$[0.243,0.771]$} \\
\hline$\theta_{C, Y}$ Consumption taxes & $G$ & 0.5 & 0.3 & 0.356 & {$[0.176,0.532]$} \\
\hline \multicolumn{6}{|c|}{ Fiscal policy rules: debt feedback coefficients } \\
\hline$\theta_{G, B}$ Gvt. consumption & $G$ & 0.4 & 0.2 & 0.131 & {$[0.062,0.198]$} \\
\hline$\theta_{I_{G}, B}$ Gvt. investment & $G$ & 0.4 & 0.2 & 0.554 & {$[0.231,0.869]$} \\
\hline$\theta_{T R, B}$ Transfers & $G$ & 0.4 & 0.2 & 0.350 & {$[0.010,0.587]$} \\
\hline$\theta_{W, B}$ Labour taxes & $G$ & 0.4 & 0.2 & 0.162 & {$[0.084,0.241]$} \\
\hline$\theta_{K, B}$ Capital taxes & $G$ & 0.4 & 0.2 & 0.154 & {$[0.045,0.256]$} \\
\hline$\theta_{C, B}$ Consumption taxes & $G$ & 0.4 & 0.2 & 0.133 & {$[0.053,0.213]$} \\
\hline
\end{tabular}

Note: ${ }^{a} \quad B$, beta; $G$, gamma; $I G$, inverse gamma; $N$, normal. 


\begin{tabular}{|c|c|c|c|c|c|}
\hline Parameter description & \multicolumn{3}{|c|}{ Prior } & \multicolumn{2}{|r|}{ Posterior } \\
\hline$\rho_{g_{z}}$ Permanent technology & $B$ & 0.85 & 0.1 & 0.807 & {$[0.672,0.994]$} \\
\hline$\rho_{\varepsilon}$ Transitory technology & $B$ & 0.85 & 0.1 & 0.914 & {$[0.845,0.982]$} \\
\hline$\rho_{i}$ Investment technology & $B$ & 0.85 & 0.1 & 0.666 & {$[0.455,0.883]$} \\
\hline$\rho_{R P^{*}}$ Foreign risk premium & $B$ & 0.85 & 0.1 & 0.993 & {$[0.987,0.999]$} \\
\hline$\rho_{\phi_{W}}$ Wage markup & $B$ & 0.85 & 0.1 & 0.293 & {$[0.172,0.417]$} \\
\hline$\rho_{\phi_{H}}$ Domestic price markup & $B$ & 0.85 & 0.1 & 0.437 & {$[0.283,0.593]$} \\
\hline$\rho_{\phi_{X}}$ Export price markup & $B$ & 0.85 & 0.1 & 0.213 & {$[0.111,0.305]$} \\
\hline$\rho_{\phi^{*}}$ Import price markup & $B$ & 0.85 & 0.1 & 0.548 & {$[0.275,0.806]$} \\
\hline$\rho_{W}$ Labour taxes & $B$ & 0.85 & 0.1 & 0.367 & {$[0.265,0.469]$} \\
\hline$\rho_{K}$ Capital taxes & $B$ & 0.85 & 0.1 & 0.445 & {$[0.318,0.572]$} \\
\hline$\rho_{C}$ Consumption taxes & $B$ & 0.85 & 0.1 & 0.370 & {$[0.265,0.476]$} \\
\hline \multicolumn{6}{|l|}{ Structural shocks } \\
\hline$\sigma_{g_{z}}$ Permanent technology & $I G$ & 0.1 & 2 & 0.170 & {$[0.105,0.232]$} \\
\hline$\sigma_{\varepsilon}$ Transitory technology & $I G$ & 0.1 & 2 & 0.545 & {$[0.414,0.670]$} \\
\hline$\sigma_{i}$ Investment technology & $I G$ & 0.1 & 2 & 0.417 & {$[0.246,0.580]$} \\
\hline$\sigma_{R P}$ Domestic risk premium & $I G$ & 0.1 & 2 & 0.338 & {$[0.188,0.485]$} \\
\hline$\sigma_{R P^{*}}$ Foreign risk premium & $I G$ & 0.1 & 2 & 0.363 & {$[0.299,0.420]$} \\
\hline$\sigma_{W}$ Wage markup & $I G$ & 0.1 & 2 & 0.585 & {$[0.471,0.692]$} \\
\hline$\sigma_{T R}$ Transfers & $I G$ & 0.1 & 2 & 6.590 & {$[5.533,7.646]$} \\
\hline$\sigma_{\tau^{w}}$ Labour taxes & $I G$ & 0.1 & 2 & 0.818 & {$[0.692,0.944]$} \\
\hline$\sigma_{\tau^{k}}$ Capital taxes & $I G$ & 0.1 & 2 & 1.850 & {$[1.559,2.162]$} \\
\hline$\sigma_{\tau^{c}}$ Consumption taxes & $I G$ & 0.1 & 2 & 0.955 & {$[0.793,1.102]$} \\
\hline
\end{tabular}

Note: ${ }^{\text {a }} B$, beta; $G$, gamma; $I G$, inverse gamma; $N$, normal.

Source: authors' compilation.

Finally, the persistence of structural shocks are all assumed to follow a beta distribution around a mean of 0.85 with standard deviation of 0.1 , while the standard deviations of the shocks themselves are assumed to follow inverse-gamma distributions around a mean of 0.1 with standard deviation of 2 .

\subsection{Estimation results}

Estimation results are summarized in Table 3. A figure showing the prior and posterior distributions is available from the authors upon request.

The posterior mean of the share of non-Ricardian households is $\omega=0.233$, which is similar to estimates in the literature for developed economies. This relatively low estimate might seem at odds with the stylized facts associated with the South African income distribution. South Africa is a highly unequal society, with a large share of the population having little to no access to financial services and/or saving and investment mechanisms. This would point to a larger share of non-Ricardian households in the model set-up. However, individuals in higher-income groups also spend more, with the larger share of total consumption expenditure focused in the middle and top income groups. Given that the model seeks to match the dynamics in total consumer spending, combined with the fact that higher-income groups likely dominate aggregate spending dynamics, it would follow that the estimated share of non-Ricardian consumers would be on the low side. 
As in Coenen et al. (2013), the model also allows transfer shocks to play a distributional role, the strength of which depends on the share parameter $\bar{\omega}$. However, given an estimate of 0.46 , the overall impact is relatively small.

The posterior mean estimate of the elasticity of substitution between private and government consumption goods is $v_{G}=1.013$, suggesting that the two goods enter the household's utility function as weak substitutes. In contrast, at 0.921 , the estimated elasticity of substitution between private and public capital, $v_{k}$, gives rise to modest complementarities in composite capital.

Turning to other parameters of interest, the investment adjustment cost parameter is substantially higher than the prior mean, while there is a high degree of habit persistence in aggregate Ricardian consumption $(\kappa=0.891)$. The estimated Calvo parameters are rather high. These estimates suggest that the Phillips curves within the model are rather flat or, in other words, that the sensitivity of inflation with respect to movements in marginal costs is low. ${ }^{15}$ The inflation indexation parameter for domestic prices is estimated around 0.5 - that is, equal weight is placed on past inflation relative to the current inflation target. For export and import prices, this weight is smaller than 0.5 .

The posterior estimates for the Taylor rule imply a large weight on interest rate stabilization. In addition, while the response to changes in inflation is smaller than under the prior, the response to changing output levels is more pronounced. Overall, the estimates suggest that while inflation targeting remains the main objective, output fluctuations (and the level of the output gap) also feature in monetary policy decisions.

Turning to the parameters of the fiscal rules, expenditure items are found to react less strongly to movements in output than taxes, with estimates of $\theta_{G, Y}=0.167, \theta_{I_{G}, Y}=0.216$, and $\theta_{T R, Y}=0.204{ }^{16}$ In contrast, there is relatively strong evidence of automatic stabilizers in the tax rules, with estimates of $\theta_{W, Y}=0.305, \theta_{K, Y}=0.507$, and $\theta_{C, Y}=0.356$. Apart from public sector investment and transfers, debt feedback coefficients are broadly similar across the different expenditure and tax rules, with the mean posterior estimates coming in at around 0.15 . In contrast, at $\theta_{I_{G}, B}=0.554$, the debt feedback coefficient in the public sector investment rule is quite large, suggesting strong use of public sector investment to stabilize public debt. This could reflect the apparent willingness of South African authorities to cut back on infrastructure budgets in the face of worsening fiscal outcomes.

The estimates for the persistence of shocks indicate that the various technology shocks and risk premium shocks are most persistent, while the fiscal shocks are least persistent. Consistent with the high weight placed on interest rate smoothing, monetary policy shocks display a low degree of volatility. Apart from public sector investment and transfer shocks, export markup shocks are the most volatile, possibly reflecting the large weight of commodities in South Africa's export basket.

\subsection{Identification and sensitivity}

Identification analysis is based on Ratto (2008) and Ratto and Iskrev (2011). Weak identification implies that changes in a particular parameter are compensated for by linear combinations of one or more other parameters (Iskrev 2010b), or that changes in a particular parameter have a negligible effect on the model moments (Andrle 2010).

\footnotetext{
15 That being said, as mentioned by Christoffel et al. (2008), the high estimates for the Calvo parameters do not necessarily imply a high degree of nominal rigidity. The reason is that the Calvo-style Phillips curve, in general, does not permit the separate identification of nominal and real rigidities that jointly influence the price-setting behaviour of firms. The inclusion of alternative sources of real rigidities could allow for the reinterpretation of the Calvo parameter estimates without affecting the slope coefficient of the Phillips curve (Christoffel et al. 2008).

${ }^{16}$ Note the signs attached to the different coefficients in the fiscal rules above. Both automatic stabilizers and the reaction to debt enter the fiscal rules with negative signs.
} 
The identification analysis shows that all model parameters in the model are identified at the posterior mean. ${ }^{17}$ Furthermore, posterior density estimates and convergence diagnostic statistics (based on Brooks and Gelman 1998) show that there is no clear indication of a problem with the optimizer. ${ }^{18}$

\subsection{Model fit and historical decomposition}

Table 4 compares several theoretical moments implied by the model to those of the observed data series in order to determine how well the model fits the data.

\begin{tabular}{|c|c|c|c|c|c|c|}
\hline & \multicolumn{2}{|c|}{$\sigma\left(x_{t}\right)$} & \multicolumn{2}{|c|}{$\rho\left(x_{t}, x_{t-1}\right)$} & \multicolumn{2}{|c|}{$\rho\left(x_{t}, y_{t}\right)$} \\
\hline & Model & Data & Model & Data & Model & Data \\
\hline$\Delta \ln \left(\tilde{Y}_{t}\right)$ & 1.875 & 0.600 & 0.194 & 0.534 & 1.000 & 1.000 \\
\hline$\Delta \ln \left(\tilde{C}_{t}\right)$ & 0.971 & 0.706 & 0.523 & 0.748 & 0.184 & 0.630 \\
\hline$\Delta \ln \left(\tilde{G}_{t}\right)$ & 0.196 & 0.903 & 0.587 & 0.449 & -0.127 & 0.245 \\
\hline$\Delta \ln \left(\tilde{I}_{t}\right)$ & 3.593 & 2.483 & 0.713 & 0.279 & -0.025 & 0.562 \\
\hline$\Delta \ln \left(\tilde{I}_{G, t}\right)$ & 4.433 & 4.311 & 0.431 & 0.364 & 0.005 & 0.135 \\
\hline$\Delta \ln \left(\tilde{X}_{t}\right)$ & 7.065 & 5.063 & 0.225 & -0.115 & 0.877 & 0.357 \\
\hline$\Delta \ln \left(\tilde{M}_{t}\right)$ & 2.810 & 3.749 & 0.519 & 0.063 & -0.019 & 0.397 \\
\hline$\Delta \ln \left(\tilde{S}_{t}\right)$ & 5.115 & 5.538 & -0.005 & 0.226 & 0.306 & 0.039 \\
\hline$\Delta \ln \left(\tilde{E}_{t}\right)$ & 1.613 & 0.687 & 0.312 & 0.284 & 0.882 & 0.377 \\
\hline$\Delta \ln \left(\tilde{W}_{t}\right)$ & 1.802 & 1.633 & 0.186 & -0.234 & 0.128 & 0.095 \\
\hline$\Delta \ln \left(\tilde{T R_{t}}\right)$ & 7.893 & 8.138 & -0.106 & -0.398 & -0.084 & -0.028 \\
\hline$\Delta \tilde{\tau}_{t}^{w}$ & 1.184 & 1.082 & -0.049 & -0.449 & 0.434 & -0.073 \\
\hline$\Delta \tilde{\tau}_{t}^{k}$ & 2.398 & 2.315 & -0.081 & -0.391 & 0.355 & 0.023 \\
\hline$\Delta \tilde{\tau}_{t}^{c}$ & 1.339 & 1.242 & -0.082 & -0.473 & 0.433 & 0.002 \\
\hline$\tilde{R}_{t}$ & 1.339 & 0.979 & 0.964 & 0.951 & -0.009 & -0.015 \\
\hline$\tilde{\pi}_{C, t}$ & 1.298 & 0.794 & 0.747 & 0.622 & -0.122 & -0.016 \\
\hline$\tilde{\pi}_{H, t}$ & 1.595 & 1.267 & 0.660 & 0.561 & -0.142 & 0.264 \\
\hline$\tilde{\pi}_{I, t}$ & 1.384 & 1.185 & 0.664 & 0.519 & -0.098 & 0.146 \\
\hline
\end{tabular}

Note: time series $x_{t}$ are the respective variables in the first column, while $y_{t}$ denotes the growth rate of output, $\Delta \ln \left(\tilde{Y}_{t}\right)$.

Source: author's calculations.

A comparison of the standard deviations (columns (2) and (3) in Table 4) shows that the model generally predicts a larger degree of volatility than observed in the data, mirroring the results of Steinbach (2014). Nevertheless, the relative magnitudes correspond. An important feature of the model, particularly in an open-economy setting, is that volatile variables such as imports, exports, and the exchange rate are accurately captured. The same rings true for the main variables of interest in this study, namely the fiscal variables. The model does an admirable job of capturing the volatility in the fiscal variables, including the relatively volatile tax rates.

Columns (4) and (5) compare the model-implied persistence with the actual persistence observed in the data. Apart from one or two exceptions, the model generally succeeds in matching the persistence observed in the data.

The final two columns of Table 4 contain the cross-correlation of the selected variables with output growth. There is a large degree of similarity — both in terms of sign and magnitude-between the modelgenerated correlations and those observed in the data. However, the model fails to replicate the (slight) pro-cyclical nature of government spending, private investment, and imports observed in the data. That being said, in general the model succeeds in matching the observed data.

\footnotetext{
${ }^{17}$ Identification analysis was carried out in Dynare. The identification procedures embedded in Dynare toolbox are largely based on Iskrev (2010a,b). Results available from the authors upon request.

${ }^{18}$ Detailed analysis and metrics available from the authors upon request.
} 
Figure 2 decomposes the model's estimate of year-on-year GDP growth (relative to the mean) into contributions from each of the estimated structural shocks. ${ }^{19}$

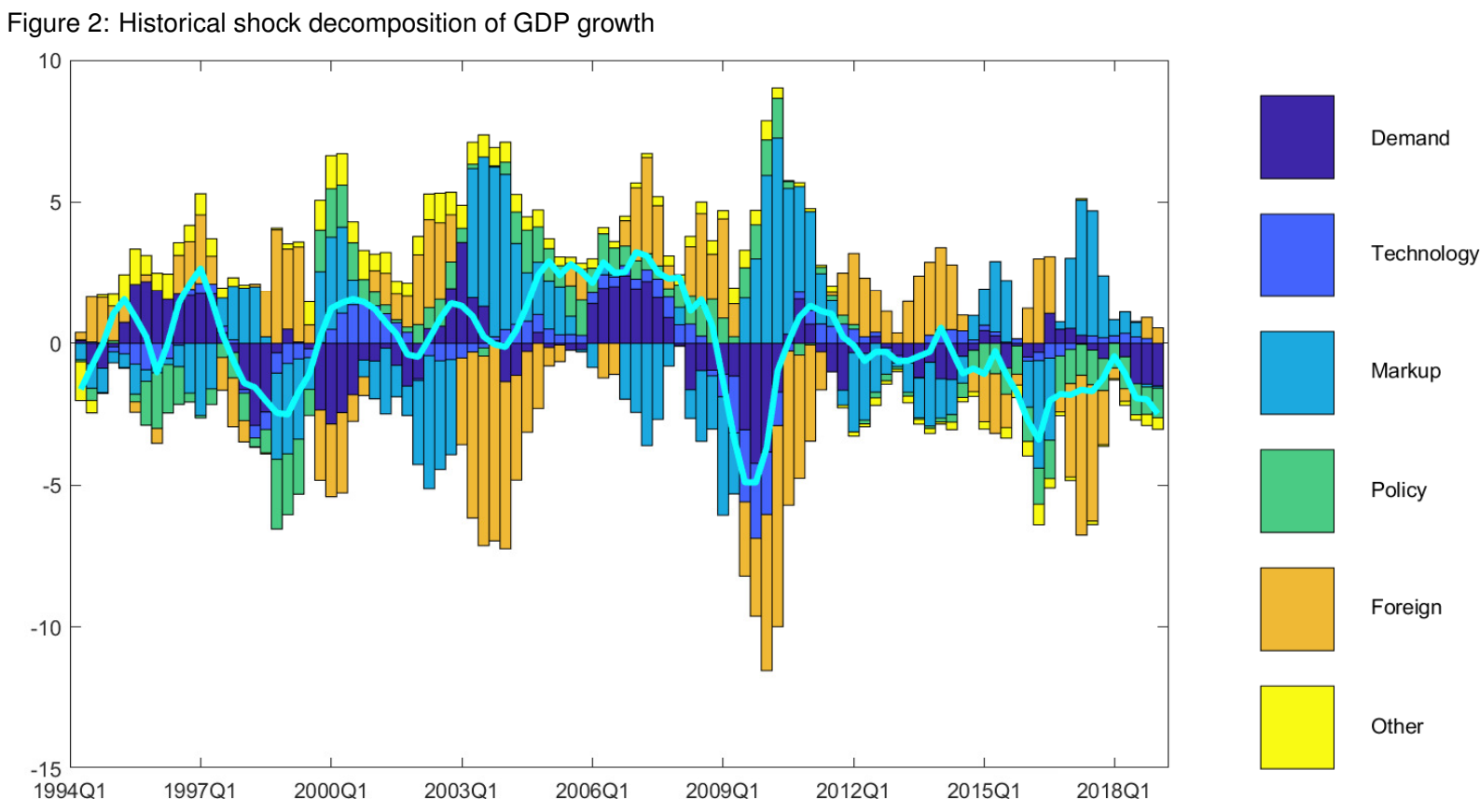

Source: author's calculations.

Developments around the exchange rate, as captured in both the markup and foreign groupings, dominated GDP growth over the period 2000-03, while demand contributed negatively over the same period. This likely reflected increased risk aversion around the turn of the century related to the emerging market crisis of the late 1990s. Between 2006 and 2008, innovations in demand and technology contributed positively to growth, while being offset by adverse supply shocks (as captured in the markup group). The negative impact of global developments becomes apparent during the GFC, both through a decline in foreign demand and a shock to export markups. The latter likely reflects the substantial fall in international commodity prices experienced at the time. Additionally, while domestic demand shocks contributed positively to growth in the lead-up to the crisis, the contribution turned negative during the crisis and has remained subdued since. The recovery in the global economy, combined with substantial monetary easing internationally, supported growth between 2012 and 2015. However, the stronger rand exchange rate and drop in commodity prices weighed on export markups. This situation has reversed since 2017, with higher commodity prices and a weaker rand exchange rate countering the slowdown in global growth to some extent. However, the former does not appear to fully offset the negative contributions from domestic demand and less accommodative domestic policy, both monetary and fiscal, over this period.

\subsection{Model dynamics}

Figures 3-6 plot impulse responses of key model variables in response to structural shocks common to standard New Keynesian DSGE models. Four distinct shocks are investigated: a shock to the domes-

\footnotetext{
${ }^{19}$ The demand shock group includes shocks to the domestic risk premium, government consumption, and government investment. The technology shock group comprises the permanent technology shock, the transitory technology shock, and the investment-specific technology shock, while the markup shock group consists of the wage markup, the domestic price markup, and the export price markup shocks. The policy shock group comprises the monetary policy shock as well as shocks to the various fiscal variables. Finally, the foreign shock group includes the external risk premium shock, the import price markup shock, and shocks to the foreign variables, including foreign output.
} 
tic policy interest rate; a transitory technology shock; a shock to the domestic price markup shock; and a shock to foreign demand. The interest rate shock gives information on the monetary policy transmission mechanism, while the other three shocks are examples of supply, cost-push, and demand shocks. $^{20}$

Figure 3 presents the response to a one standard deviation interest rate shock. The contractionary policy shock results in the standard response from model variables: a persistent decline across output, consumption, investment, and labour, and a dip in inflation. Additionally, in the open-economy setting, the appreciation of the domestic currency leads to expenditure-switching from domestic towards foreign goods. The appreciation in the real exchange rate more than offsets the drop in domestic price inflation, resulting in a contraction in exports. Imports also fall, but by less than domestic demand (on impact). The broad-based decline in aggregate demand results in cutbacks in employment and downward pressure on wages, which translates into lower pricing pressure (through the marginal cost channel). The demand response is aggravated by increased taxes and lower government spending (and transfers) in the face of a rising debt burden.

Figure 4 presents the response to a transitory technology shock. The technology shock triggers a decline in marginal cost, which causes domestic prices to fall. Domestic demand adjusts slowly to the increase in supply and, as such, both employment and nominal wages go down. However, the drop in price inflation counters the fall in nominal wages, resulting in a slight increase in the real wage. The depreciation of the real exchange rate results in a deterioration in the terms of trade and a concomitant drop in imports and improvement in exports. The rise in import prices results in a smaller decline in CPI inflation relative to domestic prices.

A shock to the domestic price markup, presented in Figure 5, results in a significant increase in domestic price inflation. The concomitant interest rate response leads to a decline in private consumption and investment. The shock to aggregate demand is exacerbated by increased taxes and decreased government spending in the face of rising debt. The appreciation in the real exchange rate results in a drop in exports and improved imports, despite the drop in aggregate demand. The decline in aggregate demand results in a decline in hours worked (employment) and exerts downward pressure on real wages.

A shock to foreign demand (Figure 6) leads to a rise in foreign inflation and the foreign interest rate. The rise in foreign inflation leads to a depreciation in the real exchange rate for the domestic economy. The depreciation in the currency combined with improved foreign demand conditions leads to a rise in exports, supporting domestic output growth. The real depreciation also results in lower import demand. Higher inflation abroad reflects higher import inflation, resulting in higher domestic price inflation and a concomitant tightening of monetary policy.

\section{$5 \quad$ The dynamic response to fiscal policy innovations}

The previous section presented the estimated model and showed that it fit the data reasonably well and responded as expected in response to key structural shocks. This section will explore the response of the model to fiscal shocks. In particular, the response of model variables to different fiscal shocks will be investigated under different debt-financing arrangements. The first subsection investigates the dynamic response to fiscal policy innovations, while the second subsection calculates fiscal multipliers under different scenarios.

\footnotetext{
${ }^{20}$ Fiscal policy shocks are discussed in the next section.
} 
Figure 3: Monetary policy shock
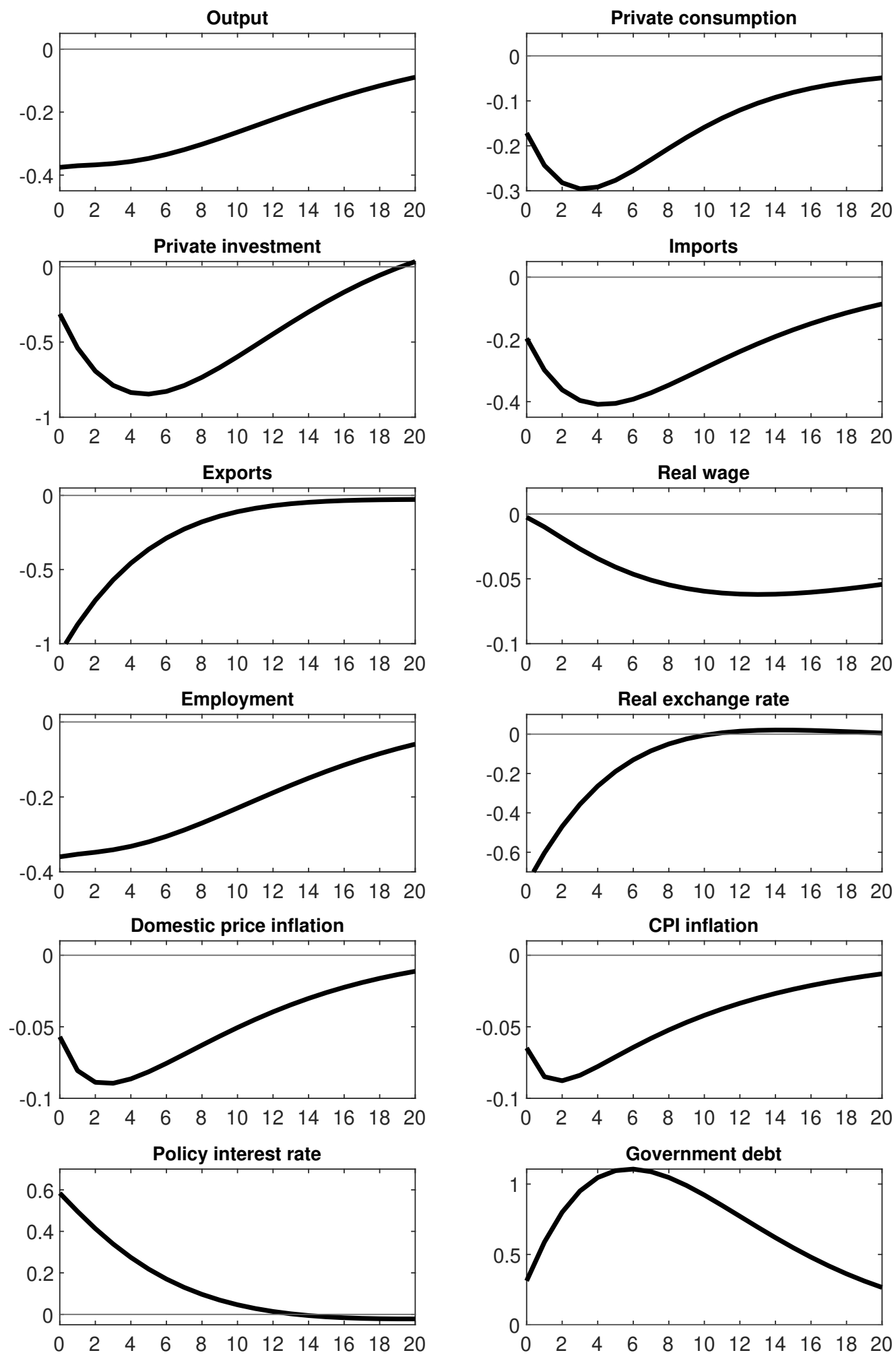

Note: all impulse responses are reported as percentage deviations from the non-stochastic steady state, except for inflation rates and the interest rate, which are reported as annualized percentage-point deviations.

Source: authors' calculations. 
Figure 4: Transitory technology shock
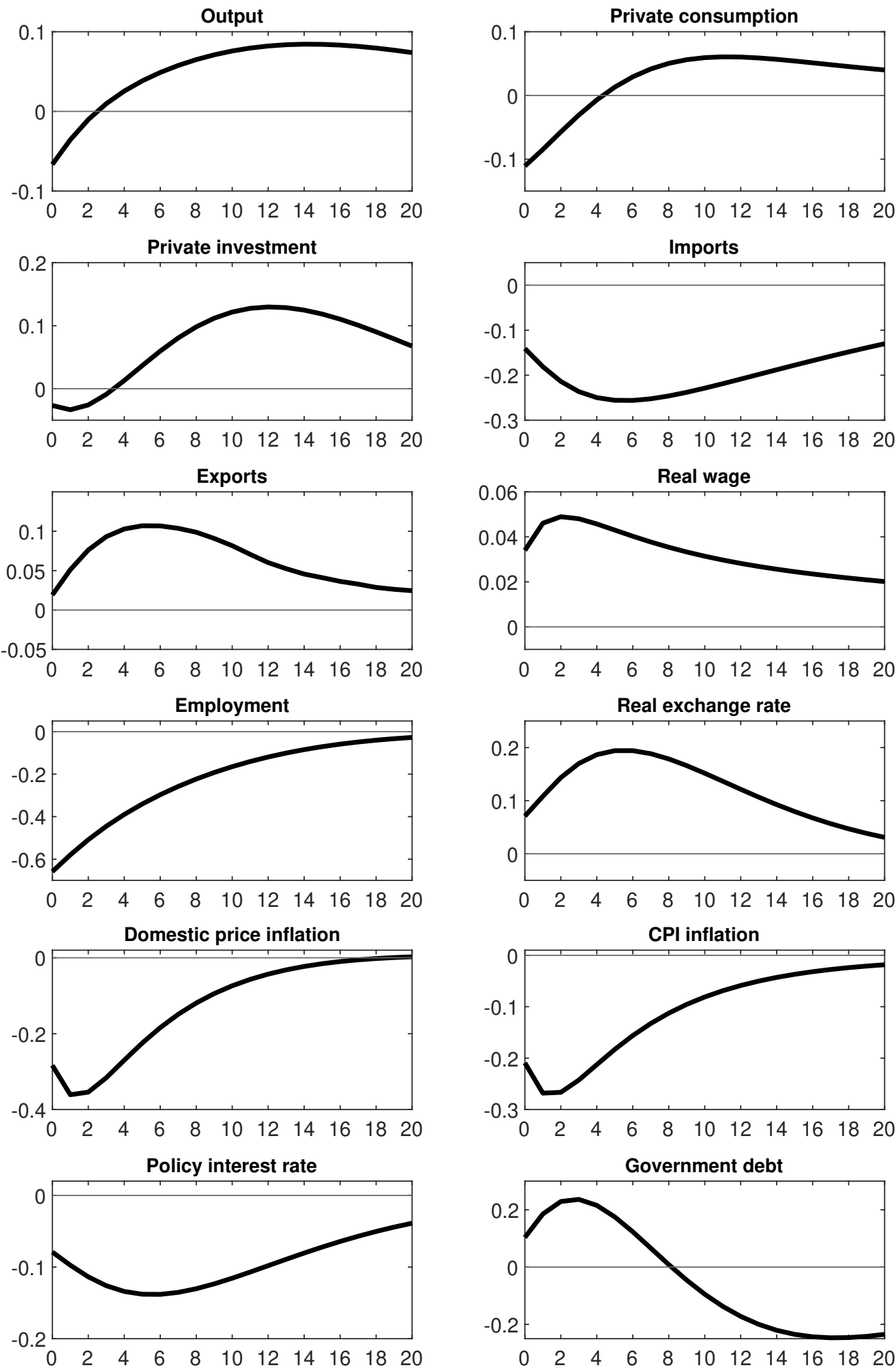

Note: all impulse responses are reported as percentage deviations from the non-stochastic steady state, except for inflation rates and the interest rate, which are reported as annualized percentage-point deviations.

Source: authors' calculations. 

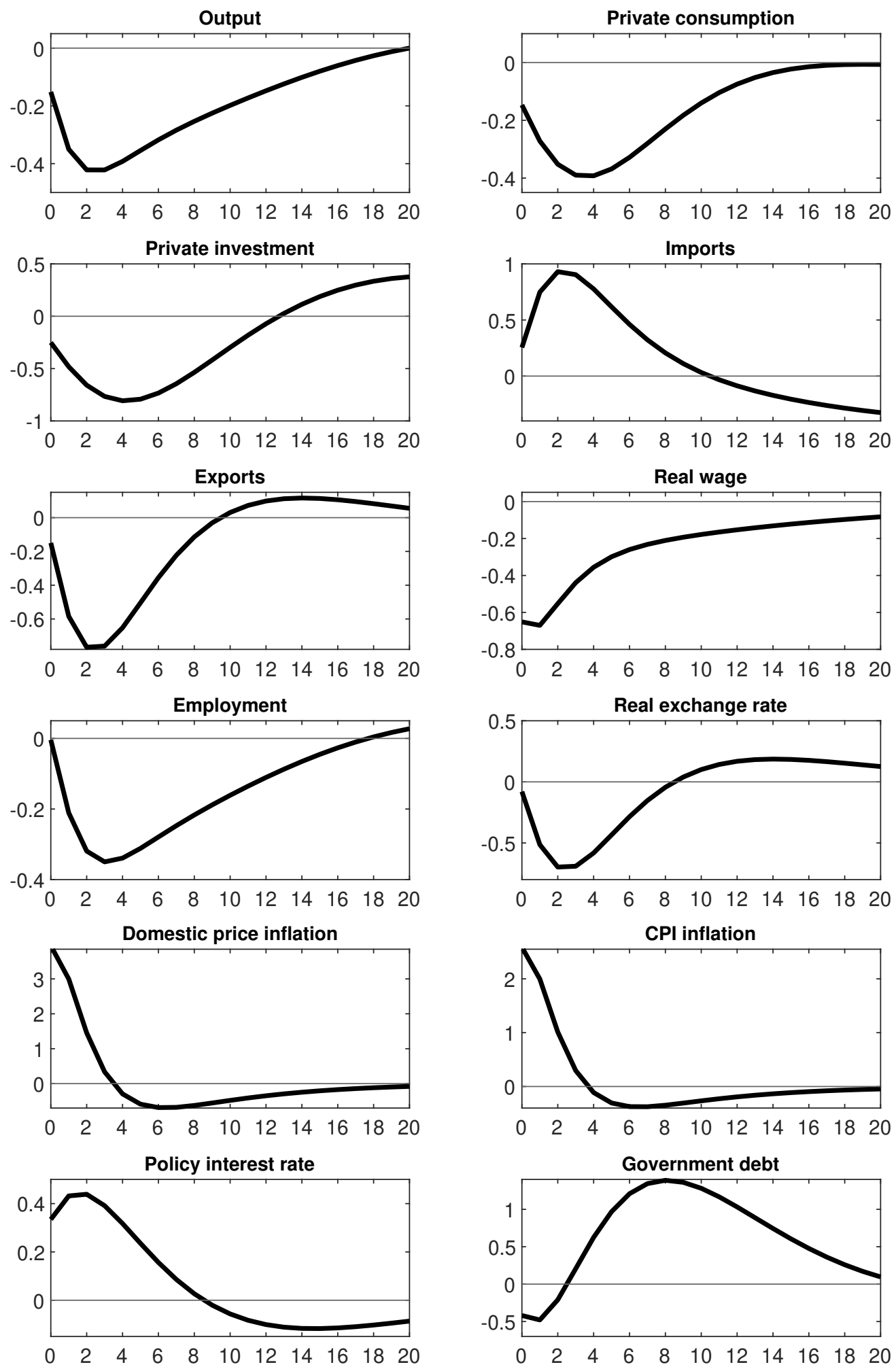

Note: all impulse responses are reported as percentage deviations from the non-stochastic steady state, except for inflation rates and the interest rate, which are reported as annualized percentage-point deviations.

Source: authors' calculations. 

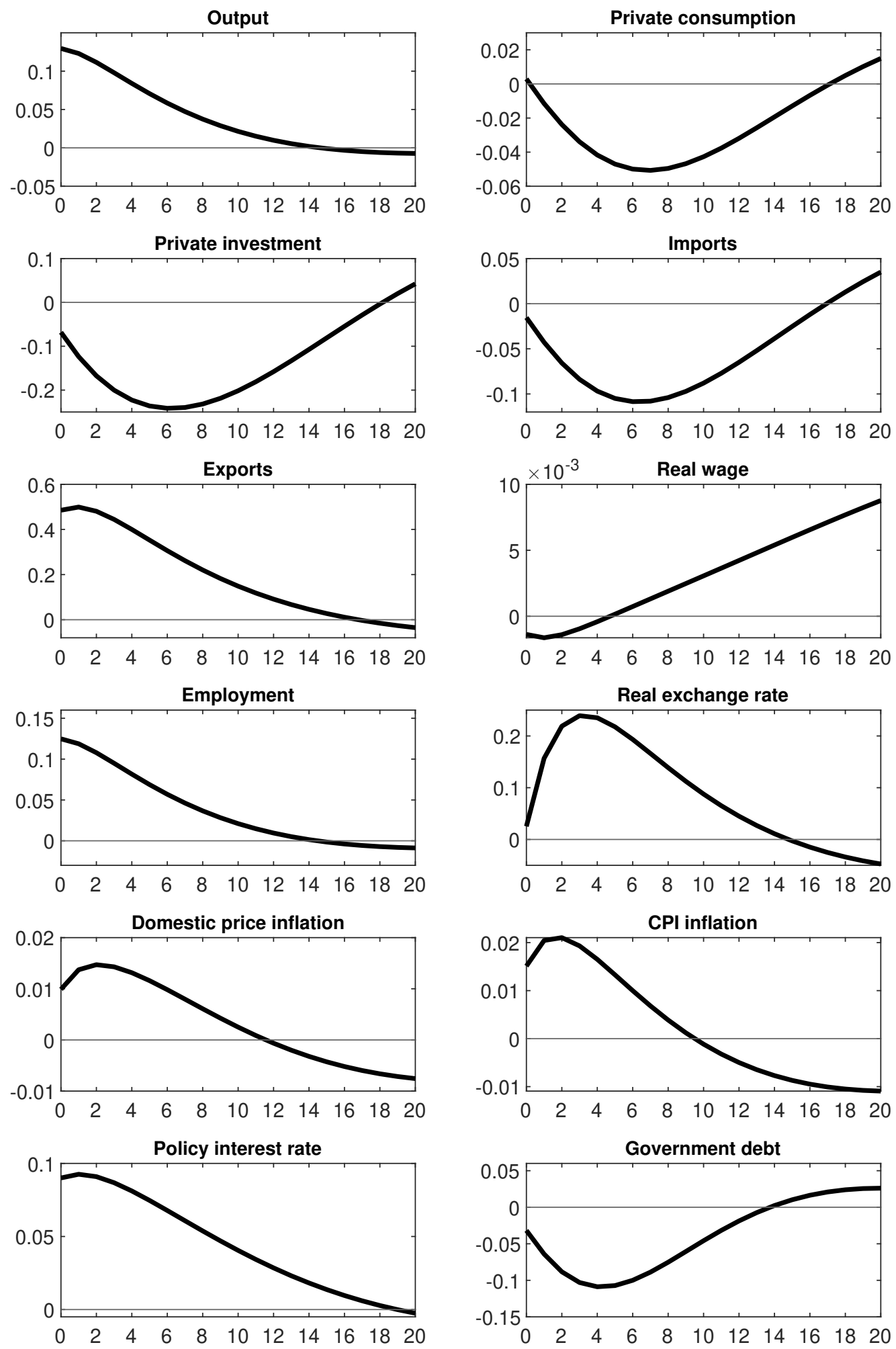

Note: all impulse responses are reported as percentage deviations from the non-stochastic steady state, except for inflation rates and the interest rate, which are reported as annualized percentage-point deviations.

Source: authors' calculations. 


\subsection{Impulse responses}

Figures 7-11 plot the impulse responses following a temporary one standard deviation exogenous increase in each fiscal instrument. Each row investigates the responses of the relevant endogenous variable under different specifications for the fiscal rules. The rules are adjusted by limiting a specific instrument or set of instruments' ability to respond to changing debt levels. That is, the debt feedback coefficients in the fiscal rules are altered. The first column in each figure represents the response of the variable in the model where all fiscal instruments respond to debt. In the second column, only transfers are allowed to respond. The third column gives the results when both government consumption spending and investment respond to debt, while the final column presents the case in which only tax rates are permitted to respond to debt. In general, as also shown by Leeper et al. (2010), the figures show that the effects of fiscal policy shocks depend crucially on the debt-financing arrangement.

Figure 7 shows the responses of output, private consumption, private investment, and government debt following a one standard deviation shock to government consumption spending. As is standard in this type of model, an increase in government spending induces a negative wealth effect, leading to an increase in labour supply and hence output. Government spending crowds out private investment, as reflected in the dip in private investment, while the negative wealth effect leads to a drop in consumption. Furthermore, government consumption enters the aggregate consumption good as a substitute to private consumption, thereby exacerbating the negative consumption response. The duration of these effects depends crucially on the debt-financing arrangement embodied in the fiscal rule. When only transfers adjust to stabilize debt, the effects are long-lasting. When only spending variables adjust, output quickly returns to its steady-state level as the subsequent decline in government consumption and investment spending in response to rising debt levels weighs on output growth. Under the assumption that only effective tax rates respond to deviations in debt, output returns to its steady-state level within five years as tax rates respond to rising debt levels. The negative response of private consumption and investment is long-lasting as the increases in distortionary labour, consumption, and capital taxes weigh on private aggregates.

The response of model variables to a shock to public sector investment is qualitatively similar (see Figure 8). However, as public capital was shown to be a complement to private capital in composite capital goods used in private production, the increased public investment expenditure and concomitant increase in public capital results in a slightly more muted (negative) private investment response. Additionally, the private consumption response turns positive after two years due to the reduction in government consumption expenditure in response to rising debt levels. Importantly, the output response following a shock to public sector investment is larger than the response following a shock to government consumption expenditure under all the alternative specifications. This suggests that public sector fixed investment is better suited to stimulating economic activity than current government expenditure.

Turning to tax shocks, Figure 9 reports the effect of a one standard deviation increase in the effective labour tax rate. The responses are broadly intuitive, with higher labour taxes inducing a negative labour supply response, which, in turn, reduces income and consumption. The reduction in labour supply also leads to a reduction in output. Once again, the duration of the effects depends crucially on the debtfinancing arrangement. It might be expected that investment will also fall since the return to capital drops as households reduce their labour supply. However, under certain financing arrangements the impact might be positive. For example, under the scenario where only taxes adjust to debt, the private investment response is (marginally) positive throughout. This is due to the decline in both consumption and capital tax rates in response to lower government debt levels. 
Figure 7: Government spending shock
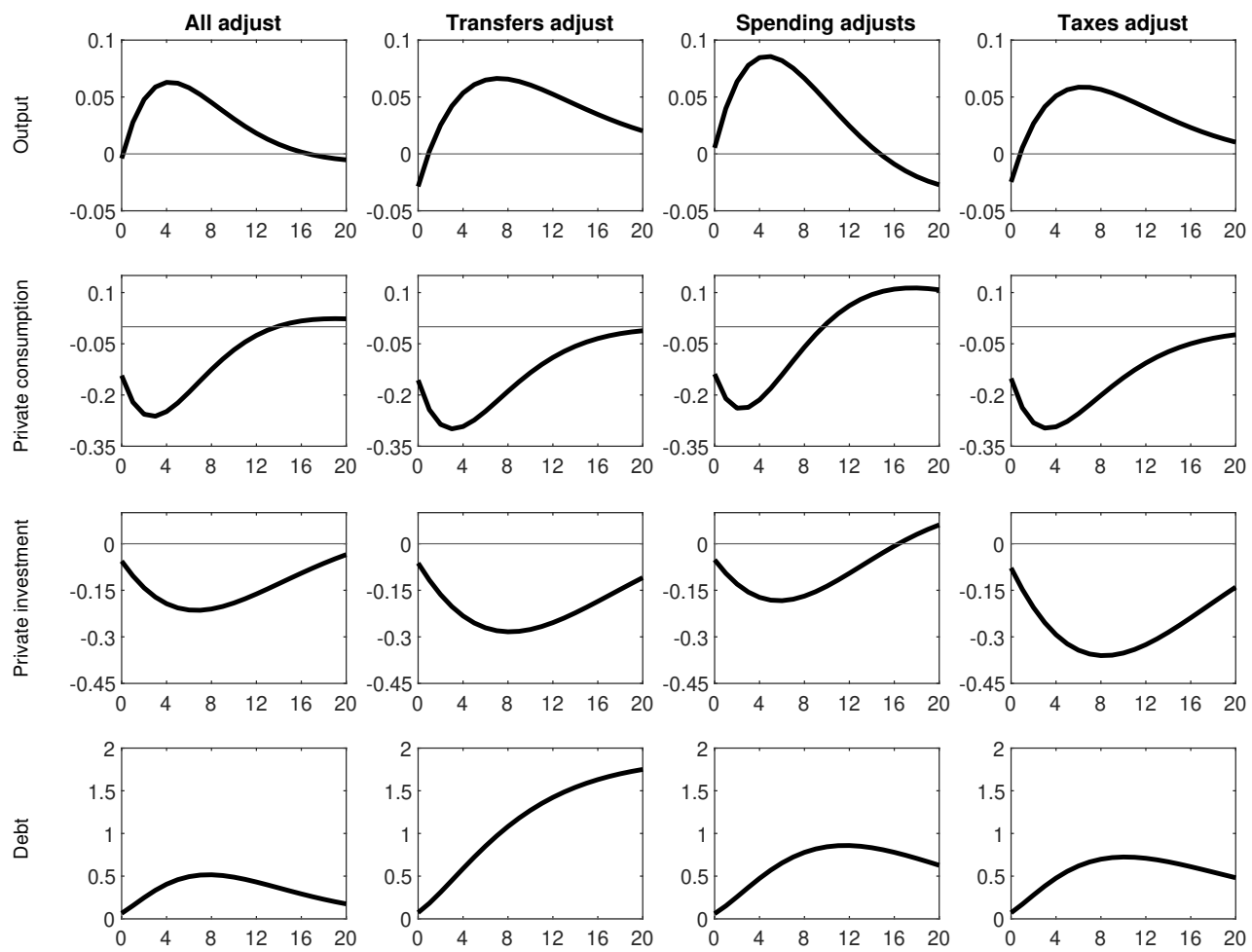

Source: authors' calculations.

Figure 8: Government investment shock
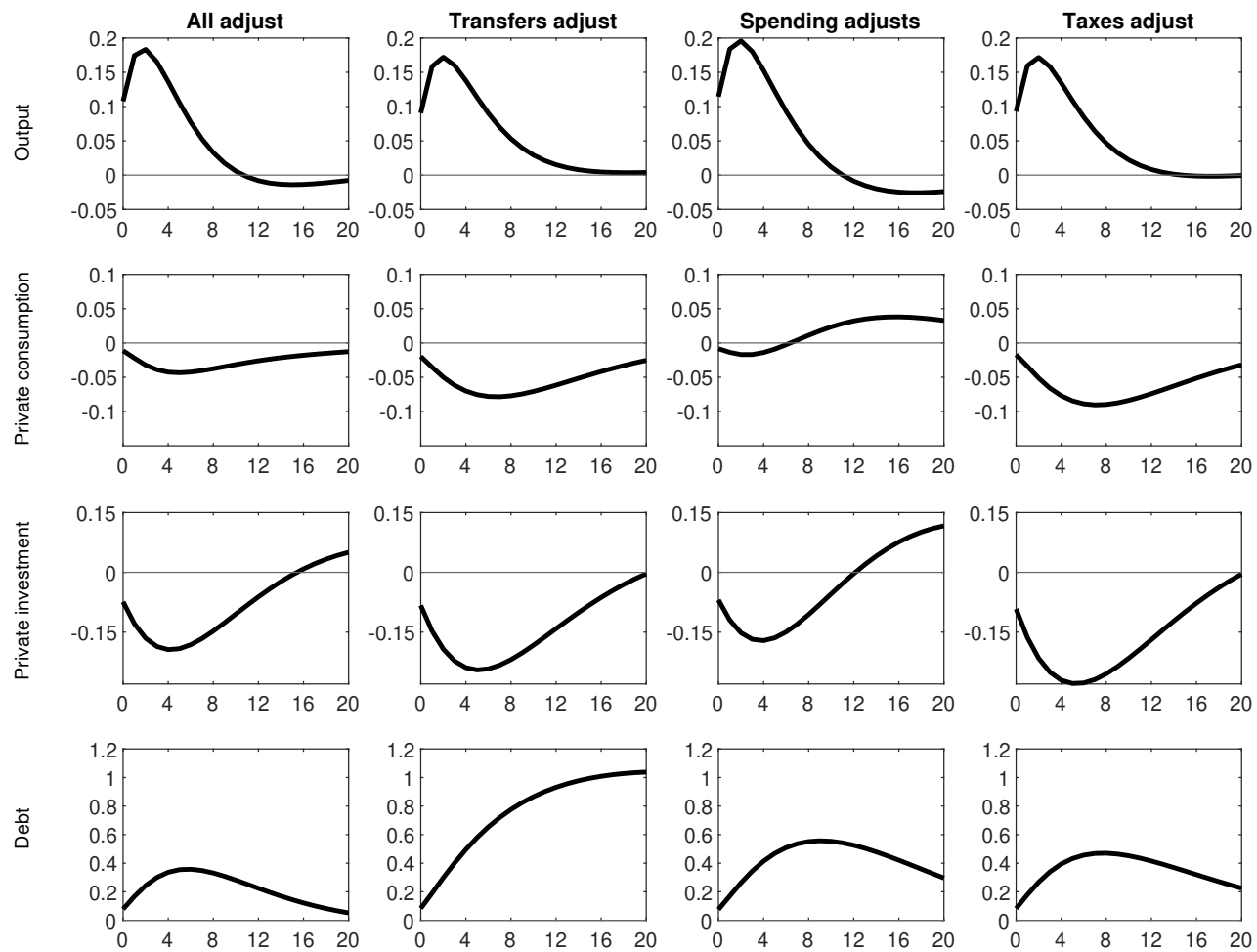

Source: authors' calculations. 
Figure 9: Labour tax shock
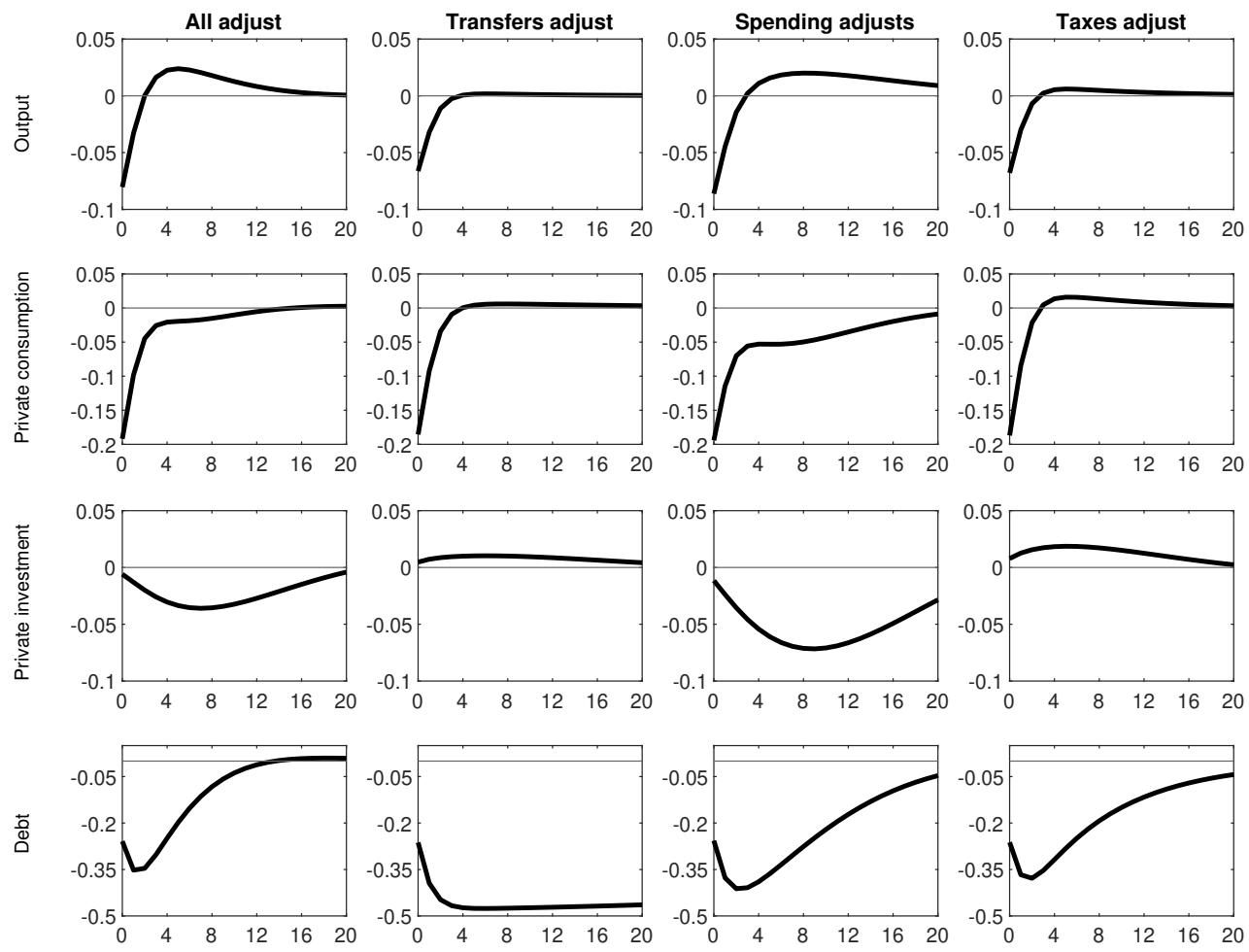

Source: authors' calculations.

Figure 10: Capital tax shock
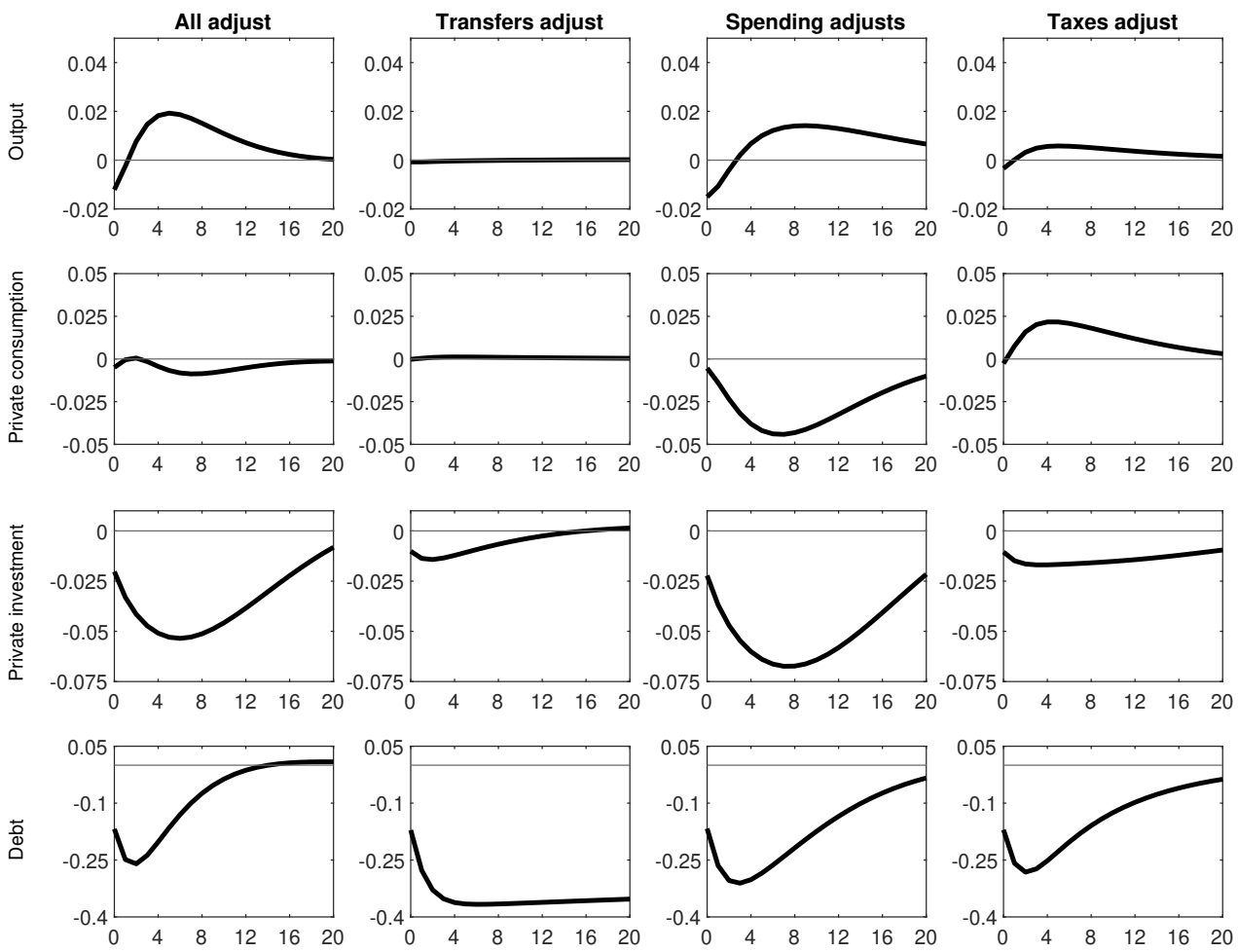

Source: authors' calculations. 

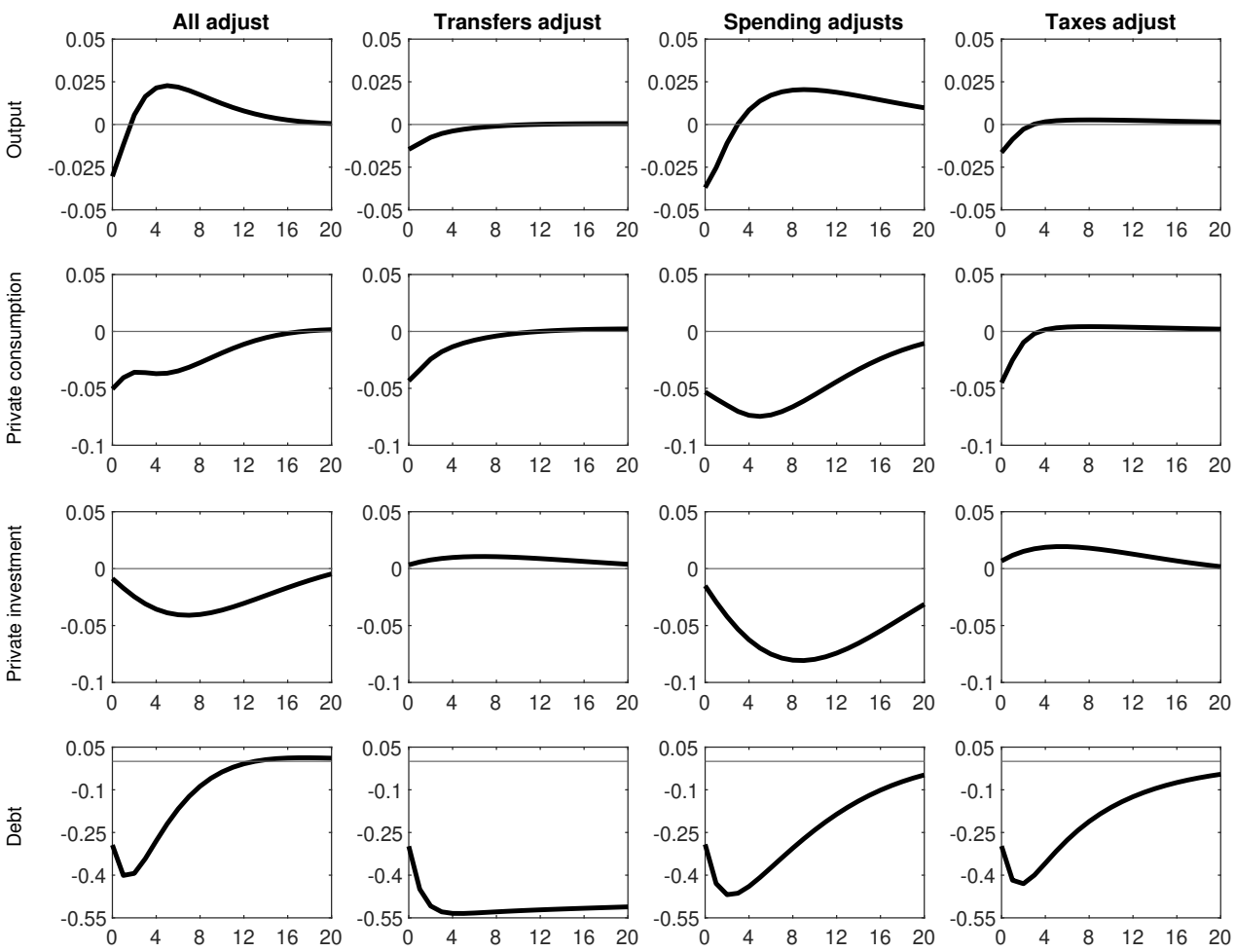

Source: authors' calculations.

Figure 10 presents the results for a one standard deviation shock to the capital tax rate. Standard theory suggests that an increase in capital taxes induces declines in private investment, labour supply, and output, while consumption rises as agents sacrifice investment for consumption (Leeper et al. 2010). However, in the current model these responses are not always apparent. As expected, the response of private investment is negative no matter what debt-financing arrangement is in place. However, the output and consumption responses depend crucially on which fiscal instruments respond to debt. When all government spending variables adjust, the output response turns positive after about a year as government consumption and investment increase following the decline in government debt. When only taxes adjust, the consumption response is positive as labour and consumption taxes fall, resulting in an expansion in output.

Finally, the response to a shock to consumption taxes is qualitatively similar to those discussed above, although the consumption and investment responses are reversed. An increase in consumption taxes reduces output on impact as consumption declines. The response of private investment depends crucially on the financing arrangement. When only spending variables adjust, the negative wealth effect of the increase in government consumption spending crowds out the effect of increased government investment spending, with the response of both private consumption and investment more pronounced than under other financing arrangements. However, when only tax rates adjust, the drop in capital tax rates result in a positive response for private investment, while the decline in consumption taxes results in a less pronounced negative response from private consumption.

\subsection{Fiscal multipliers}

The quantitative effects of fiscal policy shocks are summarized using present-value fiscal multipliers. Present-value multipliers are calculated as the ratio of the (discounted) integral of the output response 
to the integral of the government spending response. That is:

$$
\text { Present-value multiplier at horizon } k=\frac{\sum_{j=0}^{k}(1+r)^{-j} y_{t+j}}{\sum_{j=0}^{k}(1+r)^{-j} f_{t+j}} \frac{1}{f / y}
$$

where $y_{t+j}$ is the response of the GDP component at period $j, f_{t+j}$ is the response of the fiscal variable at period $j$, and $r$ is the average (model consistent) nominal policy interest rate over the sample. As before, the responses are scaled by $f / y$ (the ratio of the fiscal variable to real GDP evaluated at the sample mean). The tax response is measured as the response in total tax revenue (that is $f$ is equal to labour, capital, and consumption tax revenue when investigating the impact of unanticipated tax shocks). Present-value fiscal multipliers under the scenario when all fiscal variables respond to debt are presented in Table 5.

Table 5: Present-value multipliers: all instruments respond

\begin{tabular}{|c|c|c|c|c|c|}
\hline Variable & Q1 & Q4 & Q8 & Q20 & $\infty$ \\
\hline \multicolumn{6}{|c|}{ Government consumption multiplier } \\
\hline$\frac{\Delta Y}{\Delta G}$ & -0.04 & 0.19 & 0.21 & 0.20 & 0.20 \\
\hline$\frac{\Delta C}{\Delta G}$ & -0.82 & -0.72 & -0.64 & -0.55 & -0.55 \\
\hline$\frac{\Delta I}{\Delta G}$ & -0.07 & -0.08 & -0.10 & -0.12 & -0.11 \\
\hline \multicolumn{6}{|c|}{ Government investment multiplier } \\
\hline$\frac{\Delta Y}{\Delta I_{G}}$ & 0.56 & 0.62 & 0.57 & 0.51 & 0.51 \\
\hline$\frac{\Delta C}{\Delta I_{G}}$ & -0.04 & -0.07 & -0.09 & -0.12 & -0.12 \\
\hline$\frac{\Delta I}{\Delta I_{G}}$ & -0.05 & -0.07 & -0.09 & -0.09 & -0.09 \\
\hline \multicolumn{6}{|c|}{ Labour tax multiplier } \\
\hline$\frac{\Delta Y}{\Delta T^{w}}$ & -0.42 & -0.28 & -0.13 & -0.04 & -0.04 \\
\hline$\frac{\Delta C}{\Delta T^{w}}$ & -0.62 & -0.75 & -0.88 & -0.91 & -0.91 \\
\hline$\frac{\Delta I}{\Delta T^{w}}$ & 0.00 & -0.03 & -0.07 & -0.10 & -0.10 \\
\hline \multicolumn{6}{|c|}{ Capital tax multiplier } \\
\hline$\frac{\Delta Y}{\Delta T^{k}}$ & -0.15 & 0.10 & 0.36 & 0.49 & 0.49 \\
\hline$\frac{\Delta C}{\Delta T^{k}}$ & -0.04 & -0.04 & -0.11 & -0.17 & -0.18 \\
\hline$\frac{\Delta I}{\Delta T^{k}}$ & -0.03 & -0.13 & -0.22 & -0.31 & -0.31 \\
\hline \multicolumn{6}{|c|}{ Consumption tax multiplier } \\
\hline$\frac{\Delta Y}{\Delta T^{c}}$ & -0.19 & -0.04 & 0.14 & 0.24 & 0.24 \\
\hline$\frac{\Delta C}{\Delta T^{c}}$ & -0.19 & -0.41 & -0.60 & -0.68 & -0.68 \\
\hline$\frac{\Delta I}{\Delta T^{c}}$ & -0.01 & -0.05 & -0.09 & -0.13 & -0.13 \\
\hline
\end{tabular}

Source: authors' calculations.

Output multipliers are positive for both government spending and investment shocks. Importantly, the positive output multipliers are smaller than 1 across the board, although the public sector investment multiplier is significantly larger than the spending multiplier. Government spending and investment shocks crowd out private consumption and investment, resulting in relatively small multipliers. Consumption multipliers are negative following both a labour and consumption tax shock, while investment responds negatively to a capital tax shock. The positive output multipliers following a capital tax shock reflects the drop in tax rates and the expansion in public spending and investment in response to falling debt levels.

Present-value multipliers under other financing arrangements broadly follow the intuition of the impulse response analysis above (details are presented in Tables 6 and 7). Shocks to government investment consistently produce larger and more persistent positive effects on output (in present-value terms). In 
contrast, labour and consumption taxes are highly distortionary, resulting in relatively persistent declines in output and consumption.

Table 6: Present-value multipliers: government spending and investment respond

\begin{tabular}{|c|c|c|c|c|c|}
\hline Variable & Q1 & Q4 & Q8 & Q20 & $\infty$ \\
\hline \multicolumn{6}{|c|}{ Government consumption multiplier } \\
\hline$\frac{\Delta Y}{\Delta G}$ & 0.05 & 0.26 & 0.31 & 0.31 & 0.29 \\
\hline$\frac{\Delta C}{\Delta G}$ & -0.80 & -0.67 & -0.56 & -0.41 & -0.39 \\
\hline$\frac{\Delta I}{\Delta G}$ & -0.06 & -0.08 & -0.09 & -0.10 & -0.09 \\
\hline \multicolumn{6}{|c|}{ Government investment multiplier } \\
\hline$\frac{\Delta Y}{\Delta I_{G}}$ & 0.59 & 0.67 & 0.64 & 0.59 & 0.58 \\
\hline$\frac{\Delta C}{\Delta I_{G}}$ & -0.03 & -0.03 & -0.03 & 0.02 & 0.03 \\
\hline$\frac{\Delta I}{\Delta I_{G}}$ & -0.05 & -0.07 & -0.08 & -0.07 & -0.06 \\
\hline \multicolumn{6}{|c|}{ Labour tax multiplier } \\
\hline$\frac{\Delta Y}{\Delta T^{w}}$ & -0.45 & -0.39 & -0.27 & -0.11 & -0.09 \\
\hline$\frac{\Delta C}{\Delta T^{w}}$ & -0.63 & -0.82 & -1.02 & -1.19 & -1.19 \\
\hline$\frac{\Delta I}{\Delta T^{w}}$ & -0.01 & -0.05 & -0.11 & -0.17 & -0.17 \\
\hline \multicolumn{6}{|c|}{ Capital tax multiplier } \\
\hline$\frac{\Delta Y}{\Delta T^{k}}$ & -0.19 & -0.14 & 0.03 & 0.27 & 0.29 \\
\hline$\frac{\Delta C}{\Delta T^{k}}$ & -0.04 & -0.35 & -0.71 & -1.07 & -1.08 \\
\hline$\frac{\Delta I}{\Delta T^{k}}$ & -0.04 & -0.14 & -0.26 & -0.38 & -0.38 \\
\hline \multicolumn{6}{|c|}{ Consumption tax multiplier } \\
\hline$\frac{\Delta Y}{\Delta T^{c}}$ & -0.23 & -0.22 & -0.09 & 0.10 & 0.12 \\
\hline$\frac{\Delta C}{\Delta T^{c}}$ & -0.20 & -0.58 & -0.91 & -1.17 & -1.17 \\
\hline$\frac{\Delta I}{\Delta T^{c}}$ & -0.01 & -0.07 & -0.14 & -0.23 & -0.23 \\
\hline
\end{tabular}

Source: authors' calculations.

\subsection{Consumption multipliers and non-Ricardian households}

As mentioned earlier, a key driver of positive output multipliers in response to government spending shocks in the empirical literature is the finding that consumption reacts positively to shocks to government consumption spending. However, the evidence does not universally support the idea that higher government spending raises private consumption. In fact, the structural model in the current paper does not point to positive consumption multipliers, despite the addition of rule-of-thumb consumers.

That being said, the estimated share of non-Ricardian households in the current model set-up is quite low. The question is whether a larger share of non-Ricardian household could generate positive consumption multipliers. Table 8 presents present-value output and consumption multipliers following a shock to government spending for different assumptions regarding the share of non-Ricardian households. $^{21}$

\footnotetext{
${ }^{21}$ The table presents results for the baseline model where all fiscal instruments respond to stabilize debt, but the results are qualitatively similar for other financing arrangements.
} 
Table 7: Present-value multipliers: taxes respond

\begin{tabular}{|c|c|c|c|c|c|}
\hline Variable & Q1 & Q4 & Q8 & Q20 & $\infty$ \\
\hline \multicolumn{6}{|c|}{ Government consumption multiplier } \\
\hline$\frac{\Delta Y}{\Delta G}$ & -0.23 & 0.08 & 0.14 & 0.17 & 0.16 \\
\hline$\frac{\Delta C}{\Delta G}$ & -0.87 & -0.76 & -0.70 & -0.63 & -0.62 \\
\hline$\frac{\Delta I}{\Delta G}$ & -0.09 & -0.12 & -0.14 & -0.17 & -0.16 \\
\hline \multicolumn{6}{|c|}{ Government investment multiplier } \\
\hline$\frac{\Delta Y}{\Delta I_{G}}$ & 0.48 & 0.56 & 0.52 & 0.48 & 0.48 \\
\hline$\frac{\Delta C}{\Delta I_{G}}$ & -0.06 & -0.11 & -0.17 & -0.23 & -0.23 \\
\hline$\frac{\Delta I}{\Delta I_{G}}$ & -0.06 & -0.09 & -0.12 & -0.14 & -0.13 \\
\hline \multicolumn{6}{|c|}{ Labour tax multiplier } \\
\hline$\frac{\Delta Y}{\Delta T^{w}}$ & -0.35 & -0.33 & -0.32 & -0.30 & -0.30 \\
\hline$\frac{\Delta C}{\Delta T^{w}}$ & -0.60 & -0.58 & -0.56 & -0.54 & -0.53 \\
\hline$\frac{\Delta I}{\Delta T^{w}}$ & 0.01 & 0.03 & 0.05 & 0.07 & 0.07 \\
\hline \multicolumn{6}{|c|}{ Capital tax multiplier } \\
\hline$\frac{\Delta Y}{\Delta T^{k}}$ & -0.04 & 0.05 & 0.13 & 0.20 & 0.21 \\
\hline$\frac{\Delta C}{\Delta T^{k}}$ & -0.02 & 0.20 & 0.38 & 0.53 & 0.53 \\
\hline$\frac{\Delta I}{\Delta T^{k}}$ & -0.02 & -0.05 & -0.08 & -0.12 & -0.13 \\
\hline \multicolumn{6}{|c|}{ Consumption tax multiplier } \\
\hline$\frac{\Delta Y}{\Delta T^{c}}$ & -0.10 & -0.10 & -0.08 & -0.06 & -0.05 \\
\hline$\frac{\Delta C}{\Delta T^{c}}$ & -0.17 & -0.19 & -0.18 & -0.16 & -0.15 \\
\hline$\frac{\Delta I}{\Delta T^{c}}$ & 0.01 & 0.03 & 0.05 & 0.07 & 0.07 \\
\hline
\end{tabular}

Source: authors' calculations.

While the implied multipliers do increase with the share of non-Ricardian households, consumption multipliers never turn positive, while the output multipliers remain well below 1 . This finding is consistent with evidence for open economies (see, for example, Forni et al. 2009; Naitram et al. 2015; Ratto et al. 2006; Sin 2016). Additionally, the introduction of additional frictions in the model set-up in the form of labour and consumption taxes (which respond to debt) serves to dampen the effect of government spending increases.

Table 8: Present-value multipliers for different values of $\omega$

\begin{tabular}{|c|c|c|c|c|c|}
\hline & Q1 & Q4 & Q8 & Q20 & $\infty$ \\
\hline \multicolumn{6}{|c|}{$\omega=0.233$ (baseline estimate) } \\
\hline$\frac{\Delta Y}{\Delta G}$ & -0.04 & 0.19 & 0.21 & 0.20 & 0.20 \\
\hline$\frac{\Delta C}{\Delta G}$ & -0.82 & -0.72 & -0.64 & -0.55 & -0.55 \\
\hline \multicolumn{6}{|c|}{$\omega=0.50$} \\
\hline$\frac{\Delta Y}{\Delta I_{G}}$ & 0.07 & 0.29 & 0.30 & 0.27 & 0.27 \\
\hline$\frac{\Delta C}{\Delta I_{G}}$ & -0.574 & -0.51 & -0.49 & -0.45 & -0.45 \\
\hline \multicolumn{6}{|c|}{$\omega=0.75$} \\
\hline$\frac{\Delta Y}{\Delta T^{w}}$ & 0.20 & -0.42 & 0.41 & 0.35 & 0.34 \\
\hline$\frac{\Delta C}{\Delta T^{w}}$ & -0.27 & -0.28 & -0.30 & -0.34 & -0.35 \\
\hline \multicolumn{6}{|c|}{$\omega=0.90$} \\
\hline$\frac{\Delta Y}{\Delta T^{k}}$ & 0.29 & 0.51 & 0.49 & 0.40 & 0.38 \\
\hline$\frac{\Delta C}{\Delta T^{k}}$ & -0.07 & -0.11 & -0.18 & -0.28 & -0.30 \\
\hline
\end{tabular}

Source: authors' calculations. 


\subsection{Dynamics of debt financing}

Another question that arises relates to the efficacy of the different fiscal instruments in restoring steadystate level debt following a fiscal policy innovation. Figure 12 plots the response of government debt to a one standard deviation innovation in government consumption spending. ${ }^{22}$ Each line represents the impulse if only that specific fiscal instrument adjusts to changes in government debt.

It is clear that a spending shock results in a persistent deviation in debt from its steady-state level, regardless of the financing method. Even in the case where all instruments respond collectively, it takes several years for debt to return to its steady-state level. In terms of the individual fiscal instruments, the most effective consolidation tools appear to be government consumption spending and labour and consumption taxes. In contrast, government investment spending and capital taxes appear to be ineffective at bringing debt back to its steady-state level, even over a longer time period. The long-lasting impact of fiscal policy innovations on debt is well documented in the literature (see Leeper et al. (2010) for a particularly well-constructed contribution).

\subsection{The role of automatic stabilizers}

Assumptions regarding the role of automatic stabilizers also play an important role in debt dynamics. In the baseline results discussed above, the coefficients measuring the contemporaneous response of fiscal variables to output were set at their estimated values (as shown in Table 3).

Figure 13 presents government debt dynamics following a shock to government consumption spending and assuming all fiscal instruments adjust to stabilize debt. The figure shows results for four different assumptions regarding the automatic response of fiscal instruments to output fluctuations: no automatic response, estimated response, twice the estimated response, and three times the estimated response.

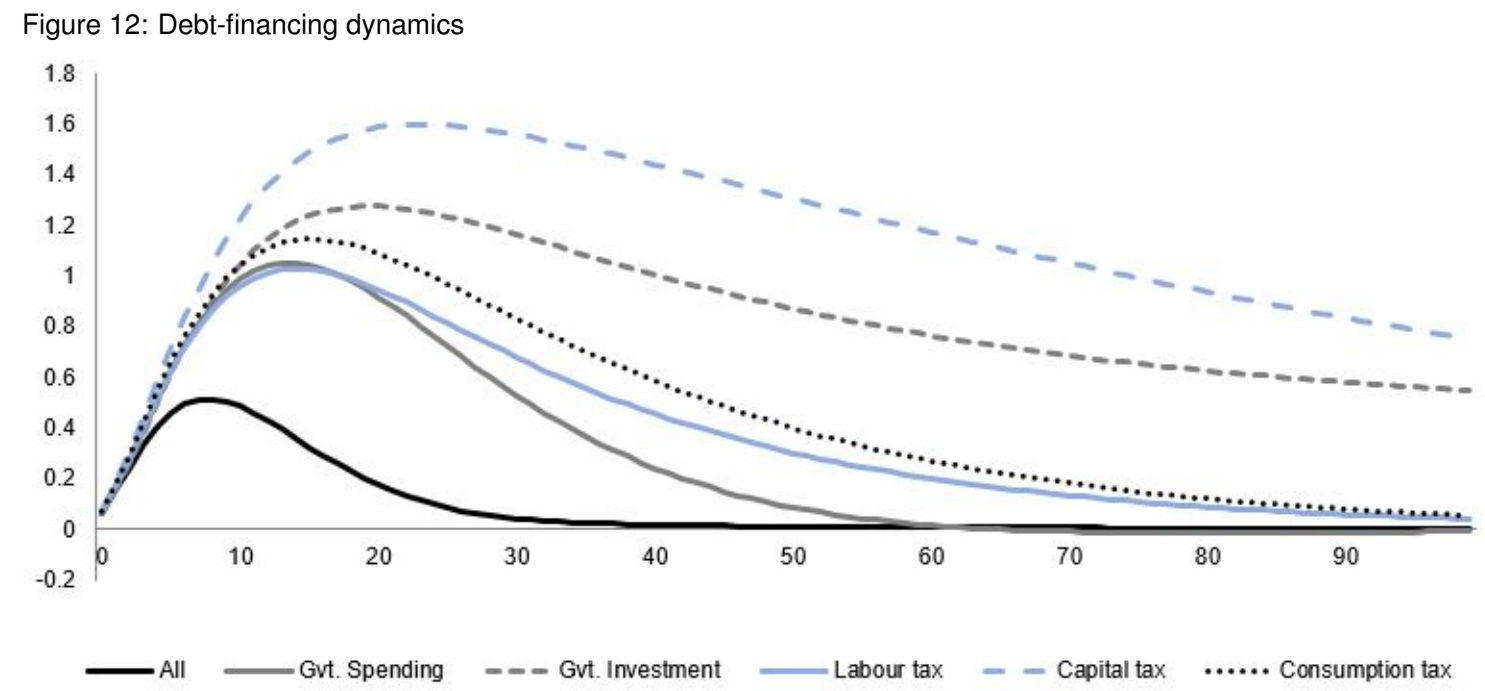

Source: authors' calculations.

\footnotetext{
${ }^{22}$ The results are shown for a shock to government spending. While the relative magnitudes and duration differ according to the initial shocked fiscal variable, the general conclusions hold for other shocks.
} 
Figure 13: Role of automatic stabilizers in debt dynamics

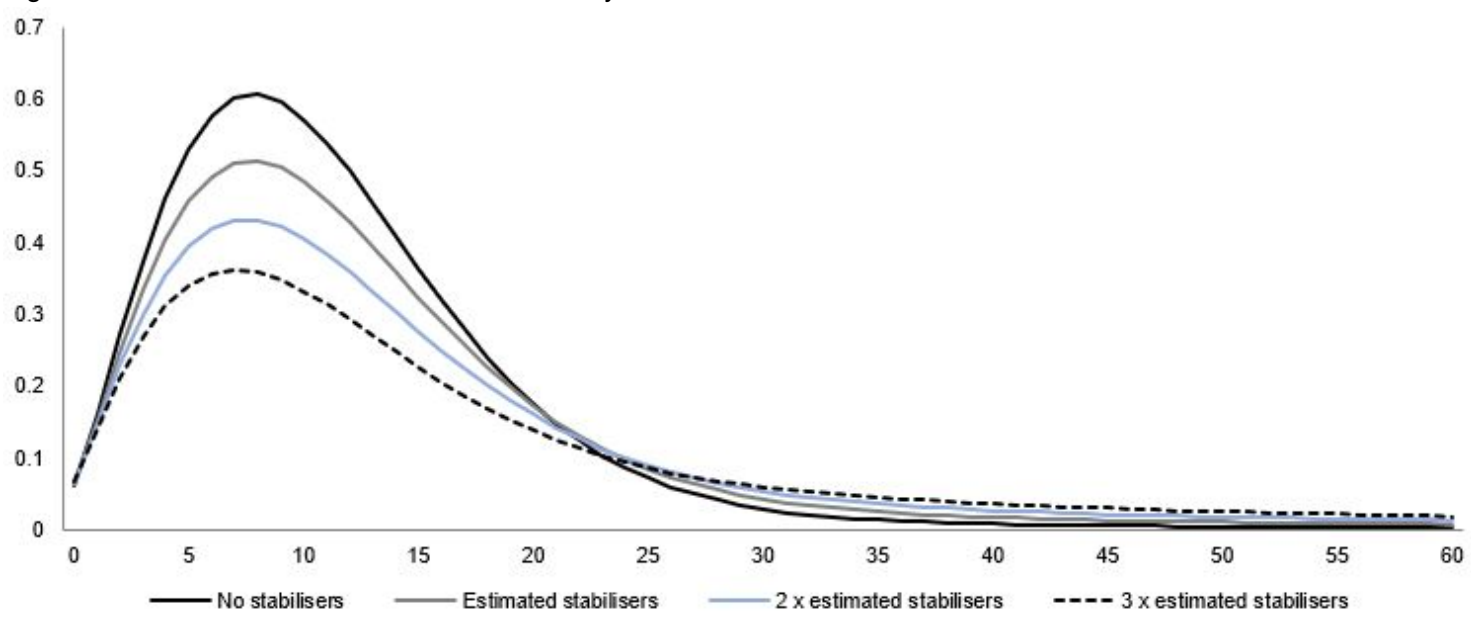

Source: authors' calculations.

Stronger automatic responses reduce short-run fluctuations, as reflected in the more muted short-term response of debt to the spending shock. However, stronger automatic responses could impose other longrun costs. Higher government spending raises output, which, under the estimated fiscal rules, induces an increase in capital and labour taxes and a decline in transfers. This, in turn, lowers output. This dynamic is more pronounced under stronger automatic stabilizers. The decline in output over the longer term reduces tax revenues, resulting in a slightly more persistent deviation from steady-state debt (see Figure $13)$.

\section{Conclusion}

In this paper, an open-economy fiscal DSGE model for the South African economy was constructed. The model includes a detailed fiscal block, as well as several other characteristics that make estimation feasible.

The estimated model fits the data reasonably well and was used to simulate the effect of innovations to the different fiscal instruments on macroeconomic aggregates, including GDP, private consumption, and investment. The results highlight the fact that the fiscal policy process is highly complex and that the impact of fiscal policy decisions on macroeconomic aggregates depends crucially on assumptions about which fiscal instruments adjust to stabilize debt.

Policy simulations indicate that government spending and investment multipliers are generally positive, albeit smaller than 1. Multipliers are also generally smaller than the estimates presented in reduced form modelling approaches, consistent with the idea that spending multipliers are smaller in open-economy settings. Second, the estimates indicate that taxes are highly distortionary, with large negative multipliers for private consumption and investment. In contrast, the impact of tax shocks on output is highly ambiguous, with assumptions regarding which instruments adjust to debt and the size of automatic stabilizers playing an important role. Finally, a look at debt dynamics indicates that government consumption spending and, to a slightly lesser extent, labour and consumption taxes are the most effective instruments for stabilizing debt after a fiscal shock. This highlights an important finding: cuts in government consumption expenditure, combined with some measure of tax increases, present the most effective options when it comes to the need for fiscal consolidation. 
That being said, conclusions about the effects of fiscal policy depend crucially on the nature of the underlying fiscal rules. As such, it is important for the researcher, and policy maker, to understand the different dynamics under different assumptions regarding the functional form of said rules.

This paper provides some insight into how fiscal policy decisions affect the economy. While the underlying dynamics are complex, the rules are relatively simple and the model economy could be expanded to include even more realistic assumptions. These could include distinguishing between productive and unproductive government spending, detailed modelling of monetary policy behaviour, regime-switching fiscal policy, expanding the model to account for differing trends in fiscal variables, and introducing fiscal foresight in the open-economy setting. ${ }^{23}$ Additionally, the analysis could be extended to consider optimal fiscal rules, as well as the differentiated impact of permanent versus temporary innovations to fiscal instruments.

\section{References}

Adolfson, M., S. Laseen, J. Linde, and M. Villani (2007). 'Bayesian Estimation of an Open Economy DSGE Model with Incomplete Pass-Through'. Journal of International Economics, 72(2): 481-511.

Alpanda, S., K. Kotzé, and G. Woglom (2010). 'The Role of the Exchange Rate in a New Keynesian DSGE Model for the South African Economy'. South African Journal of Economics, 78(2): 170-91.

An, S., and F. Schorfheide (2007). Bayesian Analysis of DSGE Models. Econometric Reviews, 26(2-4): $113-72$.

Andrle, M. (2010). 'A Note on Identification Patterns in DSGE Models'. Working Paper 1235. Frankfurt: European Central Bank.

Auerbach, A.J., and Y. Gorodnichenko (2012b). 'Measuring the Output Responses to Fiscal Policy'. American Economic Journal: Economic Policy, 4(2): 1-27.

Auerbach, A.J., and Y. Gorodnichenko (2014). 'Fiscal Multipliers in Japan'. NBER Working Paper 19911. Cambridge, MA: National Bureau of Economic Research.

Baum, A., M. Poplawski-Ribeiro, and A. Weber (2012). 'Fiscal Multipliers and the State of the Economy'. IMF Working Paper 12/286. Washington, DC: International Monetary Fund.

Baxter, M., and R.G. King (1993). 'Fiscal Policy in General Equilibrium'. American Economic Review, 83(3): 315-34.

Blanchard, O., and R. Perotti (2002). 'An Empirical Characterization of the Dynamic Effects of Changes in Government Spending and Taxes on Output'. Quarterly Journal of Economics, 117(4): 1329-68.

Bohn, H. (1995). 'The Sustainability of Budget Deficits in a Stochastic Economy'. Technical Report. Philadelphia, PA: University of Pennsylvania.

Bohn, H. (1998). 'The Behavior of U.S. Public Debt and Deficits'. Quarterly Journal of Economics, 113(3): 949-63.

Bohn, H. (2007). 'Are Stationarity and Cointegration Restrictions Really Necessary for the Intertemporal Budget Constraint?' Journal of Monetary Economics, 54(7): 1837-47.

\footnotetext{
${ }^{23}$ Jooste and Naraidoo (2017) incorporate an ad hoc measure of fiscal foresight in a calibrated, closed-economy DSGE model for South Africa.
} 
Bohn, H. (2011). 'The Economic Consequences of Rising U.S. Government Debt: Privileges at Risk'. FinanzArchiv: Public Finance Analysis, 67(3): 282-302.

Born, B., A. Peter, and J. Pfeifer (2013). 'Fiscal News and Macroeconomic Volatility'. Journal of Economic Dynamics and Control, 37(12): 2582-601.

Brooks, S.P., and A. Gelman (1998). 'General Methods for Monitoring Convergence of Iterative Simulations'. Journal of Computational and Graphical Statistics, 7(4): 434-55.

Burger, P., and M. Marinkov (2012). 'Fiscal Rules and Regime-Dependent Fiscal Reaction Functions: The South African Case'. OECD Journal on Budgeting, 12(1): 1-29.

Burger, P., K. Siebrits, and E. Calitz (2015). 'The Public Sector Balance Sheet and Fiscal Consolidation in South Africa'. Working Paper 11/2015. Stellenbosch: Stellenbosch University, Department of Economics.

Burger, P., I. Stuart, C. Jooste, and A. Cuevas (2012). 'Fiscal Sustainability and the Fiscal Reaction Function for South Africa: Assessment of the Past and Future Policy Applications'. South African Journal of Economics, 80(2): 209-27.

Calvo, G.A. (1983). 'Staggered Prices in a Utility-Maximizing Framework'. Journal of Monetary Economics, 12(3): 383-98.

Canzoneri, M.B., F. Collard, H. Dellas, and B. Diba (2015). 'Fiscal Multipliers in Recessions'. Discussion Paper 10353. London: CEPR.

Carvalho, F.A.D., and M. Valli (2011). 'Fiscal Policy in Brazil Through the Lens of an Estimated DSGE Model'. Working Paper 240. Brasilia: Central Bank of Brazil.

Cavallo, M. (2007). 'Government Consumption Expenditures and the Current Account'. Public Finance and Management, 7(1): 73-115.

Christiano, L., M. Eichenbaum, and S. Rebelo (2011). 'When Is the Government Spending Multiplier Large?' Journal of Political Economy, 119(1): 78-121.

Christiano, L.J., M. Eichenbaum, and C.L. Evans (2005). 'Nominal Rigidities and the Dynamic Effects of a Shock to Monetary Policy'. Journal of Political Economy, 113(1): 1-45.

Christoffel, K., G. Coenen, and A. Warne (2008). 'The New Area-Wide Model of the Euro Area: A Micro-Founded Open-Economy Model for Forecasting and Policy Analysis'. Working Paper 944. Frankfurt: European Central Bank.

Christoffel, K., I. Jaccard, and J. Kilponen (2011). 'Government Bond Risk Premia and the Cyclicality of Fiscal Policy'. Working Paper 1411. Frankfurt: European Central Bank.

Coenen, G., and R. Straub (2005). 'Does Government Spending Crowd in Private Consumption? Theory and Empirical Evidence for the Euro Area'. International Finance, 8(3): 435-70.

Coenen, G., R. Straub, and M. Trabandt (2012). 'Fiscal Policy and the Great Recession in the Euro Area'. American Economic Review, 102(3): 71-76.

Coenen, G., R. Straub, and M. Trabandt (2013). 'Gauging the Effects of Fiscal Stimulus Packages in the Euro Area'. Journal of Economic Dynamics and Control, 37(2): 367-86.

Davig, T., and E.M. Leeper (2011). 'Monetary-Fiscal Policy Interactions and Fiscal Stimulus'. European Economic Review, 55(2): 211-27. 
Du Plessis, S., B. Smit, and R. Steinbach (2014). 'A Medium-Sized Open Economy DSGE Model of South Africa'. Working Paper WP/14/04. Pretoria: South African Reserve Bank.

Eggertsson, G.B. (2011). 'What Fiscal Policy Is Effective at Zero Interest Rates?' In NBER Macroeconomics Annual 2010, volume 25. Cambridge, MA: National Bureau of Economic Research.

Erceg, C.J., L. Guerrieri, and C. Gust (2006). 'SIGMA: A New Open Economy Model for Policy Analysis'. International Journal of Central Banking, 2(1): 1-50.

Forni, L., L. Monteforte, and L. Sessa (2009). 'The General Equilibrium Effects of Fiscal Policy: Estimates for the Euro Area'. Journal of Public Economics, 93(3-4): 559-85.

Galí, J., J.D. López-Salido, and J. Vallés (2007). 'Understanding the Effects of Government Spending on Consumption'. Journal of the European Economic Association, 5(1): 227-70.

Hall, R.E. (2009). 'By How Much Does GDP Rise If the Government Buys More Output?' NBER Working Paper 15496. Cambridge, MA: National Bureau of Economic Research.

Horvath, R., and A. Marsal (2014). 'The Term Structure of Interest Rates in a Small Open Economy DSGE Model with Markov Switching'. FinMaP Working Paper 22. Kiel: Collaborative EU Project FinMaP - Financial Distortions and Macroeconomic Performance: Expectations, Constraints and Interaction of Agents.

Iskrev, N. (2010a). 'Evaluating the Strength of Identification in DSGE Models: An A Priori Approach'. 2010 Meeting Papers 1117. n.p.: Society for Economic Dynamics.

Iskrev, N. (2010b). 'Local Identification in DSGE Models'. Journal of Monetary Economics, 57(2): 189-202.

Jaccard, I. (2010). 'Asset Pricing, Habit Memory, and the Labor Market'. Working Paper 1163. Frankfurt: European Central Bank.

Jooste, C., G.D. Liu, and R. Naraidoo (2013). 'Analysing the Effects of Fiscal Policy Shocks in the South African Economy'. Economic Modelling, 32(C): 215-24.

Jooste, C., and R. Naraidoo (2017). 'The Macroeconomics Effects of Government Spending under Fiscal Foresight'. South African Journal of Economics, 85(1): 68-85.

Leeper, E.M., M. Plante, and N. Traum (2010). 'Dynamics of Fiscal Financing in the United States'. Journal of Econometrics, 156(2): 304-21.

Leeper, E.M., A.W. Richter, and T.B. Walker (2012). 'Quantitative Effects of Fiscal Foresight'. American Economic Journal: Economic Policy, 4(2): 115-44.

Leeper, E.M., N. Traum, and T.B. Walker (2015). 'Clearing Up the Fiscal Multiplier Morass'. Working Paper 2015-013. Bloomington, IN: Center for Applied Economics and Policy Research.

Leeper, E.M., N. Traum, and T.B. Walker (2017). ‘Clearing Up the Fiscal Multiplier Morass'. American Economic Review, 107(8): 2409-54.

Levine, P., J. Pearlman, and N. Batini (2009). 'Monetary and Fiscal Rules in an Emerging Small Open Economy'. IMF Working Paper 09/22. Washington, DC: International Monetary Fund.

Mankiw, N.G. (2000). 'The Savers-Spenders Theory of Fiscal Policy'. American Economic Review, 90(2): 120-25.

Mountford, A., and H. Uhlig (2009). 'What Are the Effects of Fiscal Policy Shocks?' Journal of Applied Econometrics, 24(6): 960-92. 
Naitram, S., J. Carter, and S. Lowe (2015). 'Three States of Fiscal Multipliers in a Small Open Economy'. Economics Bulletin, 35(1): 720-28.

Owyang, M.T., V.A. Ramey, and S. Zubairy (2013). 'Are Government Spending Multipliers Greater During Periods of Slack? Evidence from 20th Century Historical Data'. Working Paper 18769. Cambridge, MA: National Bureau of Economic Research.

Rabanal, P., and J.D. López-Salido (2006). 'Government Spending and Consumption-Hours Preferences’. Working Paper 02/2006. Valencia: La Caixa.

Ramey, V.A. (2011). 'Identifying Government Spending Shocks: It's All in the Timing'. Quarterly Journal of Economics, 126(1): 1-50.

Ratto, M. (2008). 'Analysing DSGE Models with Global Sensitivity Analysis. Computational Economics', 31(2): 115-39.

Ratto, M., and N. Iskrev (2011). 'Identification Analysis of DSGE models with DYNARE'. Mimeo. Available at: www.ifk-cfs.de/fileadmin/downloads/events/conferences/monfispol2011/ RATTO_IdentifFinal.pdf.

Ratto, M., W. Roeger, and J. in't Van (2006). 'Fiscal Policy in an Estimated Open-Economy Model for the Euro Area'. Computing in Economics and Finance Paper 2006/43. Seattle, WA: Society for Computational Economics.

Ratto, M., W. Roeger, and J. in't Veld (2007). 'Fiscal Policy in an Estimated Open-Economy Model for the Euro Area'. Economic Papers 2008-2015, 266. Brussels: Directorate General Economic and Financial Affairs (DG ECFIN), European Commission.

Ravn, M.O., S. Schmitt-Grohé, and M. Uribe (2007). 'Pricing to Habits and the Law of One Price'. American Economic Review, 97(2): 232-38.

Ravn, M.O., S. Schmitt-Grohe, M. Uribe, and L. Uuskula (2010). 'Deep Habits and the Dynamic Effects of Monetary Policy Shocks'. Journal of the Japanese and International Economies, 24(2): 236-58.

Sin, J. (2016). The Fiscal Multiplier in Small Open Economy: The Role of Liquidity Frictions. IMF Working Papers 16/138. Washington, DC: International Monetary Fund.

Smets, F., and R. Wouters (2003). 'An Estimated Dynamic Stochastic General Equilibrium Model of the Euro Area'. Journal of the European Economic Association, 1(5): 1123-75.

Smets, F., and R. Wouters (2005). 'Comparing Shocks and Frictions in US and Euro Area Business Cycles: A Bayesian DSGE Approach'. Journal of Applied Econometrics, 20(2): 161-83.

Smets, F., and R. Wouters (2007). 'Shocks and Frictions in US Business Cycles: A Bayesian DSGE Approach'. American Economic Review, 97(3): 586-606.

Stähler, N., and C. Thomas (2012). 'FiMod: A DSGE Model for Fiscal Policy Simulations'. Economic Modelling, 29(2): 239-61.

Steinbach, R. (2014). 'Essay on Dynamic Macroeconomics'. PhD Dissertation. Stellenbosch: Stellenbosch University, Department of Economics.

Varthalitis, P. (2019). 'FIR-GEM: A SOE-DSGE Model for Fiscal Policy Analysis in Ireland'. MPRA Paper 93059. Munich: University Library of Munich. 